Portland State University

PDXScholar

7-10-1996

\title{
La Protagonista en Dos Novelas Latinoamericanas Escritas por Mujeres
}

\author{
Khatereh K. Sabahi \\ Portland State University
}

Follow this and additional works at: https://pdxscholar.library.pdx.edu/open_access_etds

Part of the Spanish and Portuguese Language and Literature Commons Let us know how access to this document benefits you.

\section{Recommended Citation}

Sabahi, Khatereh K., "La Protagonista en Dos Novelas Latinoamericanas Escritas por Mujeres" (1996). Dissertations and Theses. Paper 5145.

https://doi.org/10.15760/etd.7021

This Thesis is brought to you for free and open access. It has been accepted for inclusion in Dissertations and Theses by an authorized administrator of PDXScholar. Please contact us if we can make this document more accessible: pdxscholar@pdx.edu. 


\section{THESIS APPROVAL}

The abstract and thesis of Khatereh K. Sabahi for the Master of Arts in Spanish were presented July 10, 1996, and accepted by the thesis committee and the department.

COMMITTEE APPROVALS:

George T. Cabello, Chair
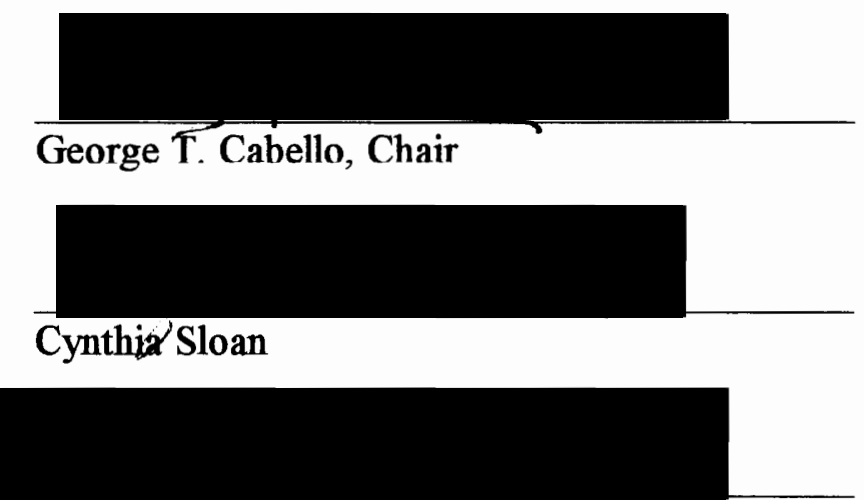

Friedrich E. Schuler

Representative of the Office of Graduate Studies

DEPARTMENT APPROVAL:

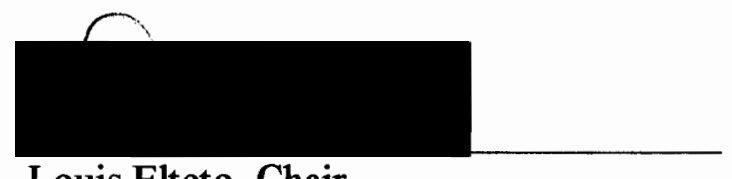

Louis Elteto, Chair

Department of Foreign Languages

ACCEPTED FOR PORTLAND STATE UNIVERSITY BY THE LIBRARY

by

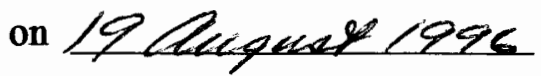




\begin{abstract}
An abstract of the thesis of Khatereh K. Sabahi for the Master of Arts in Spanish presented July 10, 1996.
\end{abstract}

Title: La protagonista en dos novelas latinoamericanas escritas por mujeres

Este estudio hace una comparación de las protagonistas de dos novelas escritas por mujeres. Analiza dos sociedades diferentes separada por el tiempo y la distancia. Trata de encontrar respuestas a las diferencias existentes, tomando en cuenta los cambios políticos, sociales y literarios que afectan a las mujeres.

Ambas novelas se centran en la mujer y su lucha contra la sociedad y la incomprensión por parte del hombre. Se hace hincapié en el tipo diferente de sociedad en que vive cada una de las protagonistas y en el papel del hombre dentro de esta sociedad. También se toma en consideración la crítica femenina contemporánea especialmente la crítica feminista francesa. Rodeando a estas dos figuras femeninas existen símbolos e imágenes, algunos, típicos de Latinoamérica y otros que son formas arquetípicas.

Otros aspectos importantes en este estudio son las consideraciones psicológicas por ejemplo, la idea del deseo, o la pregunta famosa de Freud: ¿Qué es lo que la mujer desea? ¿En qué consiste la felicidad para ella? Tratamos de encontrar respuestas a estas preguntas con un análisis detenido de los textos.

Concluimos notando que el mundo exterior e interior aprisionan totalmente a la protagonista de Última. En cambio, en Arráncame, la mujer, una figura más en control 
de su destino, que la que vemos en Última, logra romper las cadenas del sistema patriarcal. 


\section{LATINOAMERICANAS ESCRITAS POR MUJERES}

by

KHATEREH K. SABAHI

A thesis submitted in partial fulfillment of the requirements for the degree of

\section{MASTER OF ARTS \\ in \\ SPANISH}

Portland State University

1996 
I dedicate this thesis with my deepest love and affection to the memory of my father who always encouraged me to seek education and higher achievements. He was an inspiration to me and will always be. May he rest in peace! 


\section{ACKNOWLEDGMENTS}

I thank my dear husband, Hamid, for his continuous love and support and for his understanding and belief in equality of men and women.

I also want to thank my mother for raising a family of six children and giving us love and attention. I thank my older brother, Nader, who made it possible for me to come to the United States and have the opportunity to accomplish my goals. I thank my youngest brother, Mark, who has always given me solution and positive feedback in good and difficult times. I thank the rest of my family for always being there for me.

My appreciation also goes to my advisor Dr. Cabello whose patience and guidance made it easier through every step of this project.

Finally, I thank all men and women who believe in equality of the genders. 


\section{INDICE}

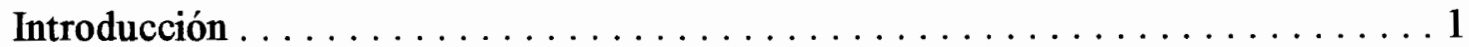

La protagonista en dos novelas latinoamericanas $\ldots \ldots \ldots \ldots \ldots \ldots \ldots$

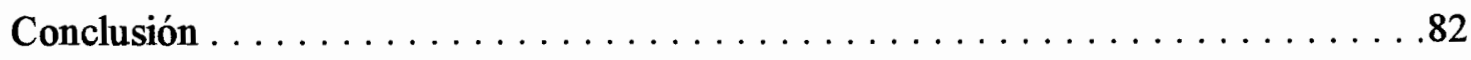

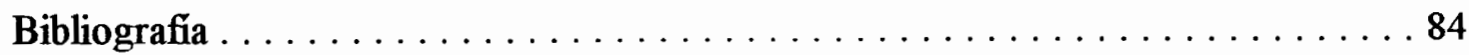




\section{Introducción}

El tema central de este estudio es una comparación entre dos novelas La última niebla de María Luisa Bombal y Arráncame la vida de Angeles Mastretta.

Específicamente es un análisis de las figuras principales femeninas en cada una de las dos novelas. Figuras que parecen tener bastante en común pero que en realidad son personajes antitéticos.

La protagonista de Bombal es una mujer infeliz en su matrimonio. Al no encontrar el amor en su matrimonio lo busca fuera de éste. Su marido que ha perdido a su primera esposa no deja de pensar en ella. Esta es básicamente la situación desesperante de la protagonista en la novela de Bombal. Es simbólico que la autora ha decidido no darle nombre al personaje principal.

En la novela de Mastretta tenemos a Catalina (Cati), una chica joven e inocente que se casa con un político y ex general. Durante la novela Catí llega a ser una mujer sofisticada, independiente y poderosa que sin embargo no está feliz con su vida. Catalina se mete en la política, como una manera de romper las limitaciones de su rol como mujer, del aburrimiento de estar todo el día en casa. Catalina se rebela contra el rol "La sufrida madre mexicana" (Paz 68). Catí es una mujer activa y agresiva y como la protagonista en la novela de Bombal busca el amor fuera del matrimonio.

En este estudio tomaremos también en cuenta el papel del hombre en Chile y en México, en sociedades básicamente patriarcales, internándonos en el papel del machismo y en el rol ideal de la mujer dentro de este marco. Ya que estamos hablando de la obra de dos mujeres cuyas protagonistas principales son también mujeres, que se enfrentan con un mundo hostil controlado por el hombre, me parece vital tomar en consideración la crítica feminista. En particular, algunas de las ideas de Cixous, Kristeva e Irigaray. Esta crítica nunca es neutral ya que se trata de denunciar las 
prácticas machistas con el propósito de erradicarlas de cuajo (Moi 10). Queremos ver si Bombal y Mastretta se adhieren a esta llamada escritura femenista y si en realidad llegan a alterar la sequencia y la lógica del lenguaje patriarcal, o son simplemente mujeres que hablan como el hombre. 
La protagonista en dos novelas latinoamericanas

Al hablar del machismo Evelyn Stevens lo describe como una forma de orgullo masculino que consta de valor y también de la agresividad masculina. En este sentido el machismo tiene dos elementos básicos: primero es el honor o la dignidad del individuo que tienen que ser protegidos. Eso lo vemos normalmente cuando el hombre defiende el honor de la mujer y de la familia. El segundo elemento "el complejo de Don Juan" quiere decir que el éxito del individuo depende de cuantas mujeres puede conquistar (Stevens 388-389).

Stevens agrega que otra de las características del machismo es la intransigencia $\mathrm{y}$ dice, "Each man is convinced that there is only one right way of doing things: his way. If his way is challenged by someone else, he may, of course, have to resort to violence to impose his criterion" (392). Como resultado de esa actitud el individuo lleva una vida solitaria y así sus relaciones personales fracasan al no querer compartir ideas y secretos con otros. Un ejemplo perfecto de estas características en la vida familiar y en la política es Andrés. Para Andrés todo se reduce al control y la única alternativa es la violencia.

Jane Jaquette nos da una definición bastante interesante, ". . . machismo, often thought by North Americans as the clearest evidence of the oppression and powerlessness of women in Latin America, is really a social convention in which women have an important stake, for male "immorality" is basic to female legitimacy and influence" (Pescatello 5). En el caso de Arráncame, al principio Catí se situa moralmente en un nivel superior al de su esposo.

Como resultado de este culto y sus características las mujeres en Latinoamérica no tienen otra opción que adaptarse a ese mundo masculino. Samuel Saldívar dice, "sólo al mantenerse dentro de su posición de doncellas castas, sumisas amas de casa y 
madres dolorosas, en fin, de seres pasivos en un mundo diseñado por los hombres, pueden sentirse seguras de siempre ser protegidas" (Citado por Fernández: 28).

Como hemos visto el machismo es un culto presente en toda Latinoamérica y tiene que ver con la práctica de situar a la mujer en una situación inferior permanente. Ya que vamos a analizar una novela de México, quiero mencionar algunos aspectos sobre la situación de la mujer mexicana y su rol dentro de la sociedad.

Justo Sierra, historiador y educador mexicano hablando de la importancia de la familia y el rol de la mujer para la estabilidad del país dijo:

In all Mexican schools we are forming men and women for the home; this is our supreme goal. Doing it, we believe firmly that we are performing a service beyond comparison with any in the benefit of the Republic .... The educated woman will be truly one for the home; she will be the companion and the collaborator of man in the formation of the family. That is what we want and that is what you are being so firmly morally prepared for . . . . You are called to form souls, to sustain the soul of your husband; for this reason, we educate you. Niña querida, do not turn feminist in our midst . . . No, you and ourselves are mutually complementary; we form a single personality called to continue the perpetual creation of the Patria. (Citado por Leacock: 66-67)

En este discurso vemos como el rol y el espacio del hombre y de la mujer están separados. El rol de la mujer ideal es ser madre y buena esposa, alguien que se sacrifica por su familia; su espacio es el del hogar donde se considera el refugio para el hombre y el que le da el sentido de seguridad. Por otro lado, el trabajo y el espacio del 
hombre es fuera de la casa y algunos trabajos como la política es considerado y estereotipado como "trabajo del hombre."

En la sociedad feudal del México colonial, el capitalismo hizo una división entre la producción social y doméstica; como resultado el trabajo doméstico pertenecía a la mujer, quien no tenía derecho de expresar su opinión y era considerada como la propiedad del hombre fuera ese su padre, hermano o marido (Leacock 85). Por ejemplo, cuando Catalina y Andrés se casan y tienen que firmar los papeles de matrimonio, el concepto de la propiedad de la mujer como un objeto es obvio. Cuando Catí firma su nombre con su apellido "Guzmán", Andrés le dice, - "De Ascencio, póngale ahí, señora - dijo Andrés que leía tras mi espalda. . . - ¿ ¿ Tú pusiste de Guzmán?- pregunté. - No mija, porque así no es la cosa. Yo te protejo a ti, no tú a mí. Tú pasas a ser de mi familia, pasas a ser mía - dijo" (Arráncame 19).

También se puede ver este concepto de la mujer como la propiedad del hombre cuando el general Gómez, borracho, le pega a su mujer en medio de la fiesta. Al pedirle Catalina a Andrés que haga algo, él responde, "¿Qué quieres que haga? Es su mujer, ¿no?" (Arráncame 134). Para Mastretta la mujer es sólo un objeto que sirve para satisfacer al hombre y éste tiene el derecho a tratarla como quiera.

El catolicismo de los años treinta defendía el concepto de la autoridad del patriarcado y la idea de la obediencia y salvación. Según la religion católica, lá mujer tenía que ser buena madre sacrificarse y obedecer a su marido. Este fenómeno era más común aún entre las mujeres de la clase trabajadora quienes tenían que estar bajo las órdenes del hacendado, el cura, el marido y de vez en cuando del hijo mayor (Leacock 89).

Octavio Paz elocuentemente nos da una imagen de la mujer en México: 
Like almost all other people, Mexicans consider women to be an instrument, either of the desires of man, or of the ends assigned to her by law, society, or moral codes. Ends, it must be said, about which she has never been consulted and in whose execution she only participates passively as depository of certain values. Whether as a prostitute, goddess, grande dame, or mistress, women transmit or preserve, but do not [create], the values and energies entrusted to them by nature or society. In a world made in man's image, women are only a reflection of masculine will and desire. (Citado por Miller: 240-241)

Podemos decir que esta imagen de la mujer en la sociedad tiene mucho que ver con la educación de las mujeres desde la niñez. Desde el principio las chicas son preparadas para el rol que está marcado por la sociedad como "femenino". Entre esos papeles, los más importantes, los que son considerados como sus deberes son ser madre sacrificada y una esposa fiel y obediente.

Por otro lado es, como menciona Thomas Bente, ". . . a cultural milieu that demand fidelity and matronly propriety from women, while at the same time disregarding amorous liaisons and external interests of men" (111). Esto quiere decir que existe un doble estándard que da más libertad al hombre y pide más responsabilidad a la mujer. Por ejemplo, cuando Andrés se da cuenta de que a Catalina le gusta Fernando Arizmendi reacciona con una actitud machista la cual se ve en la conversación siguiente, "Qué obvia eres, Catalina, dan ganas de pegarte. - Y tú eres muy disimulado, ¿no? - Yo no tengo por que disimular, yo soy un señor, tú eres una mujer y las mujeres cuando andan de cabras locas queriéndose coger a todo el que les pone a temblar el ombligo se llaman putas" (Arráncame 102). 
El hombre en el sistema patriarcal siempre ha sido superior como dice Beauvoir:

Aprisionada en la esfera de lo relativo, destinada a un hombre desde la niñez, habituada a ver en él a un ser superior que ella no puede igualar, la mujer que no ha reprimido su derecho a la humanidad soñará con hacer trascender su ser hacia uno de estos seres superiores, amalgamándose con el sujeto soberano. No existe otra alternativa para ella que perderse a sí misma en cuerpo y alma en aquél que para ella representa lo absoluto y lo esencial. (Citada por Guerra-Cunningham, Marginalidad: 55)

Vamos a analizar estas ideas más tarde en el caso de la protagonista de $L a$ última niebla, y como ella para sentirse completa sueña con un amante imaginario y lo ve como un ser perfecto.

La situación de la mujer en Latinoamérica es adaptarse y aceptar las normas de la sociedad patriarcal que considera lo masculino como superior. Esto quiere decir que sólo en los papeles impuestos a ella, como ama de casa, madre y un ser pasivo, puede sobrevivir y ser protegida y ser respetada por la sociedad y por su familia. Si la mujer decide romper estas limitaciones y normas y tener su propia voz, no será aceptada por el resto de la sociedad. El resultado será la alienación, el olvido y a veces hasta ser clasificada como loca. No hace mucho, durante los años 70 y 80 llamaban locas a las mujeres que protestaban, pacíficamente, contra la dictadura argentina en la Plaza de Mayo.

Lorna Williams describe este aspecto como un conflicto entre lo público y lo privado y dice, ". . , the conflict between the public definition of their destiny and their private notions of self-development leads to a desire to transcend the socially 
prescribed limits of their proper place. Thus, structures of escape are an essential element" (22-23). Este comentario de Williams se ve en la novela de Bombal donde el matrimonio se considera el centro de la vida para la mujer en la sociedad patriarcal. Ya que la protagonista no está satisfecha con su marido, su realización personal toma lugar en un mundo de fantasía con un amante imaginario.

Rosario Castellanos dice lo siguiente sobre la educación de la mujer:

Por eso desde que nace una mujer la educación trabaja sobre el material dado para adaptarlo a su destino y cultivarlo en un ente moralmente aceptable, es decir, socialmente útil. Así se le despoja de la espontaneidad para actuar; se le prohibe la iniciativa de decidir; se le enseña a obedecer los mandamientos de una ética que le es absolutamente ajena y que no tiene más justificación ni fundamentación que la de servir a los intereses, a los propósitos y a los fines de los demás. (Citada por Miller: 241).

Podemos notar las observaciones de Castellanos y Williams en las dos novelas analizadas en este estudio. Por ejemplo, en La última niebla vemos que el matrimonio de la protagonista con su primo Daniel desde el principio es un enlace sin amor y sólo una obligación social. Daniel sigue enamorado de su primera mujer. Como menciona Lucía Guerra-Cunningham:

Básicamente, integrarse al orden, es decir, cumplir con la meta del matrimonio, implica ser subyugada por lo que en aparencias proporcionará la realización para la existencia femenina. Sin embargo entrada en el ámbito regulado del matrimonio pone de manifiesto en toda su dramaticidad el conflicto entre el Ser y el Parecer....., búsqueda insatisfecha del amor en una sociedad que ha aniquilado 
sistemáticamente los impulsos sexuales de la mujer para reafirmar el principio de la propiedad y la instauración del nucleo familiar. (Visión 95-96)

Ellos sólo se casaron por casarse. Para Daniel su nuevo casamiento viene a llenar el vacío de su primera mujer. Se ve la indiferencia de la pareja en su conversación, - “¿Para qué nos casamos? - Por casarnos - respondo” (Última 10).

Por otro lado, ese casamiento desde el punto de vista de Daniel tiene ventajas para la protagonista cuando dice, " - ¿Sabes que has tenido una gran suerte al casarte conmigo? - Sí, lo sé- replico, cayéndome de sueño. - ¿Te hubiera gustado ser una solterona arrugada, que teje para los pobres de la hacienda? ... - Ese es el porvenir que aguarda a tus hermanas ... "(Última 10). Lo que implica que él vale más y que él le ha hecho un favor al casarse con ella. El la ha salvado a ella de tener una vida solitaria, la de una solterona. Para los lectores la ironía no puede pasar desapercibida: ¿Es peor la vida de una solterona que aquella de una esposa de Daniel?

En este comentario de Daniel se ve la importancia del matrimonio en la sociedad patriarcal. Ya que el matrimonio tiene que ser el centro de la vida de una mujer, esto le da más poder al hombre para controlar a la mujer y no darle otra elección" (Adams 16-17).

Simone de Beauvoir menciona que nuestra sociedad tradicionalmente ha ofrecido el matrimonio como único destino a la mujer. Como resultado, la existencia de la mujer ante la sociedad sólo adquiere sentido en términos del logro o fracaso en la realización de esta meta. Mientras que el hombre está categorizado según su profesión y su actividad en la sociedad patriarcal, la mujer está definida como casada, viuda, madre y esposa cuando se casa o solterona al no casarse (Citada por GuerraCunningham, Narrativa: 48). 
En el caso de.Catalina vemos también el control y dominio de Andrés desde el principio de su matrimonio sin darle ninguna otra alternativa a Catalina. Como ella misma se lo cuenta a Bibi cuando hablan de hombres y matrimonios: "Claro que yo no tuve con quien comparar, creo que ni elegir pude" (Arráncame 127). El casamiento fue algo arreglado por Andrés sin que Catalina lo supiera:

Un día pasó en la mañana. - ¿Están tus papás? - preguntó. Sí estaban, era domingo. ... - Diles que vengo por ustedes para que nos vayamos a casar. - ¿Quiénes? - pregunté. - Yo y tú - dijo - . Pero hay que llevar a los demás. - Ni siquiera me has preguntado si me quiero casar contigo dije -. ¿Quién te crees? - ¿Cómo que quién me creo? Pues me creo yo, Andrés Ascencio. No proteste y súbase al coche. (Arráncame 17)

Muy apropiados son los comentarios de Beth Miller, "In the exchange process of marriage the male assumes the position of the "buyer" who selects the "commodity," his wife, who has a direct "use-value," her ability to procreate, as well as an "indirect use-value," her ability to provide aesthetic pleasure or status to the buyer primarily because of her beauty" (286).

En la sociedad patriarcal que presenta a la mujer como objeto en el mundo del hombre, el matrimonio se convierte en una avenida por la cual la mujer cumple el proceso de su realización personal y por eso el matrimonio se considera como el centro de la vida de una mujer.

La protagonista de Bombal toma una actitud pasiva y obediente y se deja llevar y controlar por su marido porque como he mencionado antes ese es el comportamiento propio para la mujer en el patriarcado. El matrimonio de la protagonista es como un reflejo del matrimonio de María Luisa Bombal con Jorge Larco. Cuando ella se refiere a ese matrimonio dice, "Sin interés amoroso, me casé con un homosexual, artista 
pintor, confiando en un ilusorio compañerismo" (Gligo 70). En el matrimonio de Daniel con su prima, Daniel es el que sólo busca compañerismo para no estar sólo y no muestra ningún interés amoroso hacia la protagonista. En el caso de Bombal, ella es la que busca la amistad de Larco y su matrimonio está basado en un enlace amistoso.

En el caso de Catí, su matrimonio fue algo arreglado por Andrés sin ser ella consultada. Andrés elige a Catí como si fuera un objeto y no le da permiso para elegir. Andrés, que es un general, actúa como tal dando órdenes y controlando todo. Ya que Andrés es un político poderoso y la familia de Catí son de la clase trabajadora, no tienen otro remedio que obedecer las órdenes de Andrés. Catí dice, " . . le hubiera gustado tener que amenazar a mi padre. . . Le había dicho que se quería casar conmigo, que si no le parecía, tenía modo de convencerlo, por las buenas o por las malas. - Por las buenas, general, será un honor - había dicho mi padre incapaz de oponerse" (Arráncame 20). La familia de Catalina la deja casarse con Andrés porque no tienen otra alternativa, debido a su estado social, y no pueden contradecir a Andrés, un político poderoso, que hace lo que quiere.

En el matrimonio que representa Bombal en su obra, los protagonistas experimentan frustración, infidelidad y falta de comunicación sexual y espiritual. Hay muchas ocasiones durante la novela donde la protagonista expresa su infelicidad y falta de satisfacción sexual por parte de su marido. Por ejemplo, su cuerpo no es ninguna sorpresa o novedad para su marido porque como él mismo lo confiesa, lo ha visto antes, "Hasta los ocho años, nos bañaron a un tiempo en la misma bañera. Luego, verano tras verano, ocultos de bruces en la maleza, Felipe y yo hemos acechado y visto zambullirse en el río a todas las muchachas de la familia. No necesito ni siquiera desnudarte. De ti conozco hasta la cicatriz de tu operación de apendicitis" (Última 10). Este comentario de Daniel indica que para él su mujer no tiene, fisicamente, 
ningún atractivo. El tedio y el vacío es algo constante que rodea a la protagonista de Bombal, sentimiento que continúa por años; “Como para compensar la indiferencia en medio de la cual se efectuó hace años nuestro enlace, hay ahora un exceso de abrazos, de regalos y una gran comida con numerosos brindis. En la mesa, la mirada displicente de Daniel tropieza con la mía" (Última 25).

Las dos protagonistas buscan el amor verdadero fuera del matrimonio. En el caso de Catí, su adulterio empieza cuando ella se da cuenta de las relaciones de Andrés con otras mujeres. Catalina sabe que Andrés comparte su cuerpo, su dinero y su amor con otras mujeres y como resultado tiene otros hijos. Vemos que al principio de su matrimonio ella estaba enamorada de Andrés y siempre quería estar a su lado. En una frase menciona su necesidad de Andrés diciendo, "Me faltaban reproches para contar mi aburrimiento, mi miedo cuando despertaba sin él en la cama, .. . Me volví inútil, rara. Empecé a odiar los días que él no llegaba, . . . enfurecer cuando era tarde y él no llamaba por teléfono, no aparecía, ... esperando que él llegara de repente y le diera a todo su razón de ser" (Arráncame 143-144). Estas últimas palabras: "le diera a todo su razón de ser," indican entonces como la mujer se ha creado una vida donde el hombre no es sólo algo importante sino, más aún, algo primordial. Ella ha centrado todo su interés alrededor de su esposo y al hacerlo ha perdido la poca libertad que tenía.

Poco a poco esta actitud de dependencia y fidelidad de Catalina hacia Andrés cambia. Está deseosa de romper sus cadenas y se interesa en todos los asuntos políticos de Andrés. Al hacerlo ambos empiezan a trabajar juntos durante el día y esto tampoco satisface a Catalina:

Siempre creí que lo único necesario para vivir tranquila era tener a Andrés todos los días conmigo. Pero cuando la mañana siguiente en lugar de salir corriendo me anunció que pensaba quedarse y que iba a 
cambiar su oficina a nuestra biblioteca yo hubiera querido desaparecerlo. Era como tener un ropero antiguo a media casa, para donde uno volteara aparecía. (Arráncame 163)

Las relaciones íntimas que Catalina tuvo con Carlos Vives tuvieron un efecto enorme en su personalidad. Catí se atreve a romper las normas de la sociedad patriarcal donde tener relaciones fuera del matrimonio se considera un gran pecado para la mujer. Catalina ya no es una chica inocente y humilde sino que es una mujer madura, además, esposa de un gobernador. Danny Anderson comenta, “. . , wealth and social status alone provide Cati a means of resisting women's traditional social scripts within her own social class" (23). Ella confiesa su infidelidad y su relación con Carlos, 'Me volví infiel mucho antes de tocar a Carlos Vives. . . Nunca quise así a Andrés, ... Me daba vergüenza estar así por un hombre" (Arráncame 164).

Todo este sentimiento y pasión es nuevo para ella porque en el caso de Carlos, ella fue la que lo elegió, y no fue algo arreglado como su matrimonio. Es su primer amor. Las canciones que canta Toña también son significantes en este sentido. Por ejemplo, la canción de "la noche de anoche" que como Catí dice, "imaginé escrita para mí" que sigue así, "Ay qué noche la de anoche," ..., "De momento tantas cosas sucedieron que me confundieron," ..., "Te lo juro, todo es nuevo para mí,"..., "Que me hizo comprender que yo he vivido esperándote" (Arráncame 190). Como se ve las palabras de la canción reflejan los sentimientos experimentados por Catalina al estar con Carlos.

En la obra de Bombal, la protagonista empieza su imaginario adulterio cuando se da cuenta de que su marido no la ama y sólo la quiere para reemplazar a su primera mujer difunta quien según él era "perfecta". Daniel no le muestra cariño y no aprecia su belleza y por eso la protagonista se siente desesperada por no ser aceptada y amada. 
Esta falta de amor, y la pérdida de su identidad, al tener que substituir a otra persona le hacen construir su mundo de fantasía, y un amante imaginario. Al contrario de Catalina, la protagonista de Bombal no se atreve a tener un amante real y se conforma con soñar su amante. Ella decide permanecer dentro de esos límites y por eso su proceso hacia el desarrollo personal es un proceso interior y de fantasía (Williams 26).

A pesar de las diferencias entre la personalidad de las dos protagonistas, las novelas de Bombal y de Mastretta son diferentes también según el espacio y el tiempo histórico. Es importante indicar que las dos novelas, La última niebla y Arráncame la vida están separadas no sólo por el espacio sino también por el tiempo. La última niebla fue escrita en Chile en 1935, y Arráncame la vida en México en 1985. La sociedad chilena de 1935 es una sociedad ordenada, tradicional, controlada por la oligarquía (Skidmore 124-125). En las primeras páginas de Arráncame la vida, vemos a Catí, una adolecente, durante los años de la Revolución Mexicana. Vemos una sociedad en caos donde el coraje personal y el oportunismo creaba líderes y generales de la noche a la mañana (Meyer 579). Andrés como Catí es de origen humilde; gracias a su inteligencia, empuje, y a a veces, su brutalidad logra distinguirse llegando a general de ejército y luego gobernador del estado de Puebla.

La sociedad mexicana entonces, comparada con la chilena de esos años, es una sociedad con gran fluidez y enormes cambios donde la mujer muchas veces, como soldadera, compartió con el hombre la lucha armada. Las dos novelas transcurren entonces durante aproximadamente los mismos años. Catí entonces tiene más posibilidades de libertad y de poder desarrollar su propia personalidad. En cambio la protagonista de la novela de Bombal está atrapada, como rodeada de una niebla patriarcal espesa que la aprisiona. 
El espacio fisico que se relaciona con la posición social de las protagonistas, afecta su actitud, impone limitaciones y normas culturales. Por ejemplo, la protagonista de Bombal vive fuera de la ciudad donde no tiene mucho contacto con la gente y no está metida en los asuntos sociales y políticos y su actividad fuera del hogar es mínimo. La única vez que ella va a la ciudad es cuando van a visitar a la familia de su esposo. Williams menciona, "For her, a change of locale means the substitution of one domestic sphere for another rather than an opportunity to broaden her knowlege of the workings of the larger society" (23). Su contacto se limita al círculo familiar y como consecuencia no tiene tanta oportunidad para conocer a otra gente, para crecer y desarrollar su propia personalidad.

También en un pueblo la infidelidad sería un escándalo mayor que en una ciudad grande y creo que por esas razones la protagonista de Bombal decide alejarse del mundo exterior y de la realidad y crear un mundo de fantasía inventando a su amante. Como menciona Rita Gnutzmann, "María Luisa Bombal, de la alta burguesía, describe el mundo del latifundismo patriarcal a comienzos de nuestro siglo y plasma la situación de la mujer desocupada, reducida al hogar. La única forma de liberación del mundo banal es el refugio en los sueños y en la escritura" (93). Ella inventa ese mundo imaginario y a su amante porque no ve otra alternativa para sobrevivir. Ella se da cuenta que la única manera de estar feliz es escaparse de la realidad de su vida y del matrimonio con un hombre indiferente. Los hombres, dice Carmelo Urza: 
... fail to fulfill the needs of their spouses, offering only mechanical social roles to play out and material wealth. Marriage has been transformed into so much merchandise. This falsification of sentiments does not, however, motivate the women into declaring conjugal war, but rather forces them to passing escape into memory/fantasy in order to achieve the ilusion of love and communication. (96)

Daniel no la quiere como ella es, sino, sólo por representar la figura, aunque en forma imperfecta, de su primera mujer que ha muerto. La protagonista siente dolor, luego indiferencia buscando una salida a su tragedia en los sueños. Claudio Waller Orlandi hablando de las ideas de Freud acerca del sueño dice, "Freud treats the dream as a system of repressed desire and proclaims that the content of the dream is ... the fulfillment of a wish, ..." (235). Ya que en el sistema patriarcal el hombre es la figura perfecta, la mujer tiene que identificarse con ese ser perfecto para realizar su felicidad y el amor y por eso la invención del amante es necesario. Ya que la protagonista no se atreve a romper las normas de la sociedad explicitamente, es decir tener un amante real como Catí; implicitamente a través del sueño y fantasía rompe estos limites e inventa su propio mundo imaginario.

Bombal misma clasifica su técnica narrativa como prosa surrealista. Para Bretón:

el surrealismo busca la creación imaginaria de un mundo interior en el que se exploran las diferentes posibilidades del subconsciente. Negando 
el mundo exterior en favor de "yo", el individuo - según los surrealistas - logra, a su modo, una mayor conciencia de su propio $<<$ ser $>>$. Bretón afirma que el sueño es la única vía que permite al hombre realizar ampliamente sus facultades, el que produce una solución auténtica y el que ayuda a la solución de los problemas vitales. (Citado por Fernández: 67-68)

Para la protagonista de Última, la única solución para escaparse de su matrimonio infeliz es refugiarse dentro de sí misma y soñar un amor ideal y un matrimonio feliz, lo que no ha logrado en el mundo real.

Alberto Rábago concluye diciendo:

Al no poder la protagonista encontrar a Daniel, su marido, un eco a su deseo de creatividad emocional, se produce en ella una petrificación existencial y un desconocimiento de su dignidad de mujer que sólo podrá ser superado por la imaginación, al crear otra realidad. ... turbada por el miedo a ser despersonalizada, no pretende escapar, desde su punto de vista, a un mundo, ideal o irreal, sino crear imaginativamente su propio mundo real. (Citado por Fernández: 68)

María Luisa Bombal misma en una entrevista habla sobre el uso de los sueños y fantasía en su obra diciendo, "Lo que uno tiene lo perfecciona en sus sueños. Es soñar lo que esto hubiera podido ser o intentar lo que se quisiera. Porque la heroína no tiene nada inventa el personaje de sus sueños (sic)" (Gálvez Lira 108). Así que, en una 
sociedad que está dominada por el poder del hombre y no deja ningún lugar a la mujer, el único refugio de la mujer es en el mundo de la fantasía y el sueño porque allí sí que la mujer está en control y el hombre no puede llegar.

Como el sueño y fantasía, el adulterio es otra manera de escapar para la mujer. El adulterio de las dos protagonistas es una manera de expresar su desventura en el matrimonio y en el caso de Catalina que es más rebelde y más activa que la protagonista de Bombal, esa infidelidad es una rebelión contra los derechos y el estereotipo del rol femenino impuesto a la mujer por la sociedad patriarcal. Ella sabe que Andrés ha tenido y tiene varios amantes, e incluso hijos con estas mujeres. Catí herida y sintiéndose usada no se va a refugiar en los sueños sino que va a luchar contra lo que considera injusto haciendo lo mismo que hace Andrés.

Catí, de este momento en adelante, si se siente atraida por un hombre va a saltar en la cama con él, "Desde que vi a Fernando Arizmendi me dieron ganas de meterme a una cama con él. ... Andrés se dió cuenta y terminó con la fiesta" (Arráncame 101). Es una expresión de venganza y también una busca del verdadero amor. Un personaje al actuar o no actuar se define. Catí ya está más libre y tiene relaciones sexuales con otros hombres como lo hace Andrés con otras mujeres. Catí ya no es una chica inocente quien oía todas las instrucciones de Andrés y le tenía miedo, sino que es una mujer madura que quiere participar en los asuntos de Andrés. Ella ya no tiene miedo de Andrés diciendo, “- Ya me cansé de mi marido. . . . Ya no tengo miedo" (Arráncame 215,223). Se ve que el amor verdadero es lo más importante para Catí y 
cuando está haciendo el amor con Carlos ya no le importa nada, "Era yo sin recordar a mi papá, sin mis hijos ni mi casa, ni mi marido, ni mis ganas del mar" (Arráncame 215). Se oyen ruidos de cadenas rotas; una persona, no totalmente, pero ya más libre.

Para Hélène Cixous la sexualidad de la mujer y su cuerpo es lo más importante para el desarrollo de su personalidad y la afirmación de su identidad. Sostiene que:

Todo lo que tenga que ver con el cuerpo debe ser explorado, desde sus funciones a su libido, a su imagen; una vez hecho esto se debe observar como todo ello se transforma en el nivel simbólico. Las mujeres deben escribir su cuerpo y al hacerlo liberarán su inconsciente que ha sido silenciado hasta ahora. (Citada por Agosín, Silencio: 14)

Catalina durante toda la novela critica la expectación social de la mujer como madre, esposa o la primera dama del estado. Catalina protesta contra la sociedad que quiere que ella sea, “. . p parte de la decoración, alguien a quien se le corren las atenciones que habría que tener con un mueble si de repente se sentara a la mesa y sonriera ... . la cosa era ser bonita, dulce, impecable" (Anderson 17).

A Catí no le importa lo que la gente piensa de ella y siempre dice lo que quiere a pesar de las limitaciones de su rol como mujer. Esa violación de los límites sociales en el comportamiento de Catí se ve también en otras ocaciones sociales. Dorothy Smith comenta:

Debido al alejamiento de la localización del aparato gubernativo, los hombres otorgan una importancia creciente a los lazos derivados de sus 
negocios o de sus asociaciones profesionales. Se produce una separación característica entre las zonas de actividad social de hombres y mujeres. La de los hombres se articula cada vez más en relación a su trabajo y la de las mujeres en relación a su responsabilidad en el barrio residencial, dedicadas al cuidado de los hijos y al trabajo cotidiano de ocho a seis en el hogar. Esta separación se hace tangible en reuniones sociales, donde la conversación separa a los hombres de las mujeres.

Esta división de espacio y conversación se ve durante una cena en la casa de Catalina que dice:

Prefería oír la plática de los hombres, pero no era correcto. Siempre las cenas se dividían así, de un lado los hombres y en el otro nosotras hablando de partos, sirvientas y peinados. El maravilloso mundo de la mujer, llamaba Andrés eso. . . Como yo colocaba las tarjetas con los nombres y sentaba a cada quien donde me convenía, me acomodé junto a Sergio Cuenca que era un hombre guapo y buen conversador a quien yo invitaba a las cenas aunque no viniera al caso porque era de los pocos amigos de Andrés que me divertían. Le gustaba llevar la conversación y si yo me sentaba junto a él podía decir bajito cosas que quería que se dijeran alto sin decirlas yo. (Arráncame 81) 
Aunque la sociedad patriarcal controla el comportamiento de la mujer en cuanto a lo que es "correcto" Catalina se rebela contra las normas a través de otras técnicas como menciona Anderson:

... Catí does not passively conform to such prescriptions for she tacitly controls the seating at the dinner table and creatively gives expression to her muted voice through a male guest who is allowed to participate in the conversation. It is, nevertheless, once again the cultural ideal of male dominance that constrains Catí and it is through a man that she must maneuver her access to the conversation. (20)

Catí prefiere participar en la conversación de los hombres porque ella siempre se rebela contra el estereotipo de los roles femeninos o como Andrés lo llama "el maravilloso mundo de la mujer." Catalina por ser la esposa del gobernador no tiene que hacer todos los trabajos que las otras mujeres hacen por ser amas de casa. Ella tiene sirvientes, choferes y cocineros y por eso se aburre y quiere meterse en los asuntos de los hombres. En otra ocasión cuando habla con Chofi sobre el discurso de Fito acerca de la maternidad dice:

... tuve la nefasta ocurrencia de disertar sobre las incomodidades, lastres y obligaciones espeluznantes de la maternidad. . . Resultaba entonces que mi amor por los hijos de Andrés era un invento, que cómo podría decirse que los quería si ni siquiera me daba orgullo ser madre de 
los que parí. No me disculpé, ni alegué a mi favor ni me importó parecerles una bruja. (Arráncame 273)

Ella piensa como un hombre, siempre, rechazando las responsabilidades que tiene por ser mujer como la maternidad y el parto. Esta manera de pensar no es muy común y tradicional entre otras mujeres porque para ellas la maternidad es una gran experiencia y una bendición. Catalina renuncia a su rol como madre en una conversación con Bibi que se queja de estar embarazada diciendo, “ - ¿Son horribles las panzas, no? - Horribles. Yo no sé quién inventó que las mujeres somos felices y bellas embarazadas. - Seguro fueron los hombres. ... Yo mis dos embarazos los pasé furiosa. Qué milagro de la vida ni qué la fregada" (Arráncame 129).

La obra de Bombal tiene su protagonista sin nombre; técnica narrativa que enfatiza la pérdida de la identidad. Con esto Bombal trata de darnos el mensaje que su protagonista no representa sólo a una mujer sino a muchas otras que como ella buscan el amor que no encuentran en su matrimonio (Agosín, Apreciaciones 231). Para Hernán Vidal el problema central de la situación de la mujer chilena es político, “. . . las heroinas de la autora son víctimas de un régimen social burgués que oprime a las mujeres convirtiéndolas en seres enajenados" (Citado por Agosín, Recuerdo: 404-405).

Frente a una insatisfacción sexual y un matrimonio en ruinas, la protagonista se aleja del mundo exterior y se encarcela en un mundo interior construido por ella. Durante este proceso empieza la búsqueda de su identidad. Su realización personal tiene que tener otro hombre como su objetivo. René Girard ha salido con una 
interesante interpretación del personaje en la novela. El deseo del protagonista pasa a formar un "triángulo del deseo" o sea el deseo de acuerdo con el otro (5). Catí como también la protagonista de Última están imitando modelos que ellas en su fantasía han elegido libremente. Girard nos da como ejemplo a Emma Bovary y a don Quijote entre otros. En otras palabras Catí y la esposa de Daniel necesitan seguir un modelo, exterior o interior, para poder conseguir sus deseos.

Para ella la felicidad consiste en tener un cuerpo bonito y un hombre que la quiera y la aprecie como ella misma lo dice, “ . . soy bella y feliz! Sí, ¡ feliz!, la felicidad no es más que tener un cuerpo joven y esbelto y ágil" (Última 12). Esta desesperada dependencia a un hombre es la razón de inventar al amante. Su unión sexual, la cual fue satisfactoria y pasional, la hace feliz por cierto tiempo.

Una autora o un autor mete en su obra creativa parte de su propia vida. María Luisa Bombal no es una excepción. El dolor y la desilusión de la esposa de Daniel es un reflejo de la propia vida de Bombal. Su matrimonio con el pintor argentino Jorge Larcos fue un fracaso; y, su amor no correspondido, por Eulogio Sánchez, un industrial chileno, casado, fue una tragedia. Incluso, en un momento de desesperación María Luisa trató de matar a Eulogio con una pistola. Ella misma se confiesa, "Yo nunca tuve tino en el amor. Ese es un hecho. Al enamorarme perdía un amigo y lo reemplazaba por una tragedia" (Agosín, Biografia 328).

Para Bombal la felicidad absoluta no existe; y, en una entrevista con Gloria Gálvez Lira ella describe la felicidad diciendo, “. . . la felicidad no existe. Los 
latinoamericanos viven buscándola. Momentos existen. La felicidad permanente no existe. La felicidad consiste en gozar los momentos, gozar de las pequeñas cosas - la amistad - por ejemplo" (108).

La obra de Bombal presenta a la mujer como un ser sentimental y pasional que busca amor y aventuras pero al mismo tiempo es víctima de esa sensualidad que la hace frágil y pasiva. Como menciona Agosín, "La literatura de la Bombal no es sólo un postulado de ciertas construcciones ideológicas motivadas por roles, definiciones, valores impuestos por un orden patriarcal imperante sino que, su obra postula una búsqueda del deseo y de la imaginación liberadora por medio de la invención y la memoria" (Silencio 34).

Para María Luisa el amor es la parte más importante de la vida de una mujer: "El hombre es intelecto; sabe más; es $<<$ the power behind the throne. $>>$ La mujer es sentimiento, es armonía. Yo creo que el amor es lo más importante en la vida de una mujer. La mujer es puro corazón a diferencia del hombre que es la materia gris y el iniciador de todas las grandes empresas" (Guerra-Cunningham, Entrevista 126).

En otra entrevista sobre la misión de la mujer y del hombre dice:

¿Por qué pedirle al hombre que sienta como nosotras? Mientras que la vida de casi todas las mujeres parece haber sido hecha para vivir un gran amor, un solo amor con toda su belleza y su dolor, la misión del hombre en este mundo al parecer no es la misma. Pero yo creo en nuestra misión de amar, aunque en estos días las mujeres se han inclinado hacia 
una actitud algo así como un orgullo intelectual de no creer en el amor. (Gligo 132)

Aunque María Luisa cree que amar es la misión de la mujer y parece apoyar los estereotipos que se aplican a la mujer, pero al presentar a esas mujeres frustradas e infelices trata de resistir las normas sociales y la injusticia hacia la mujer y sus limitaciones. Lagos-Pope señala, 'La utilización de caracterizaciones tradicionales no necesariamente es indicación de una posición convencional o antifeminista, sino que puede revelar la profundidad y complejidad de los conflictos que expresa la mujer escritora, ... (Citada por Agosín, Apreciaciones: 123).

La protagonista de Bombal se da cuenta de que ya el sueño terminó. Otra vez tiene que enfrentarse con su vida cotidiana aburrida y vivir y obedecer a un marido que no la quiere. Por fin se conforma con su destino y decide continuar diciendo, 'Lo sigo para llevar a cabo una infinidad de pequeños menesteres; para cumplir con una infinidad de frivolidades amenas; para llorar por costumbre y sonreír por deber. Lo sigo para vivir correctamente, para morir correctamente, algún día" (Última 43).

Ella ya no tiene ninguna esperanza y su vida es sólo una vida vacía y sin amor. Ella vive por vivir, únicamente, como el acto físico de comer y respirar sin ningún aspecto espiritual. La protagonista decide reaccionar de una manera indiferente ya que no tiene ninguna razón para estar contenta y feliz. Ella sólo trata de cumplir con su deber en una sociedad patriarcal donde el hombre está en el poder y hasta su muerte no 
está bajo su propio control y tiene que vivir de la manera que la sociedad le exige, es decir "correctamente".

Quiero hablar ahora de la naturaleza y los símbolos que están presentes en las dos obras y que tienen suma importancia en el desarrollo de las novelas. Rita Felski describe la naturaleza y su relación con la mujer diciendo, "Nature is often viewed as an extension of some kind of 'femenine' principle; the violation of the natural world is perceived to reflect the oppression of women, the refusal of the values of an industrialized and urbanized modernity simultaneously functions as a search for a lost female self, a return to origins" (132).

En la novela hay una escena que se puede considerar como una violación de la naturaleza y la oppresión sexual de la mujer. Cuando el amante de Regina vuelve de caza con los otros, “. . deja caer sobre mis rodillas una torcaza aún caliente y que destila sangre" (Última 16). El acto de cazar es una violación al orden de la naturaleza y el calor y la sangre por su simbolismo de color rojo se puede interpretar como la pasión y el dominio sexual del hombre sobre la mujer (Bente 105). Esta es una escena ambivalente donde la protagonista experimenta atracción y repulsión: "Pego un alarido y la rechazo, nerviosa. Mientras todos se alejan riendo, el cazador se obstina en mantener, contra mi voluntad, aquel vergonzoso trofeo en mi regazo. Me debato como puedo y llorando casi de indignación" (Última 16).

El acto de cazar según Cirlot representa también el deseo y la muerte (146147), y Chetwynd agrega que cazar es un acto de persecusión (25-26). Podemos 
interpretar los símbolos en esta escena de la novela de Bombal. El amante de Regina quiere tentar a la protagonista. Para el amante conquistar a las mujeres, como lo ha hecho con Regina es un paralelo de la caza. Persigue a las mujeres que son infelices en su matrimonio creyendo que buscan el amor en otro lugar y con otro hombre que no sea su marido.

El amante ve esta necesidad en la protagonista y quiere satisfacerla como lo hace con Regina. Eso desde el punto de vista del machismo satisface su ego como hombre al poder cazar a estas mujeres casadas. En este sentido, esta escena representa, para el amante, el deseo, que según Lao-Tse es el enemigo interior (Cirlot 146). Vemos también que los pájaros que el amante de Regina deja caer sobre las rodillas de la protagonista, todavía están caliente aunque están muertos. Esto puede simbolizar la vida de la protagonista que está entre la vida y la muerte. Ella vive, pero espiritualmente está muerta y su vida sólo es un acto físico de comer y dormir y, "para llorar por costumbre y sonreír por deber" (Última 43). Podemos agregar que el pájaro tanto como el pez son símbolos fálicos (Cirlot 26) y, bien conocidos en la cultura popular chilena.

Por supuesto, en la obra de Bombal la niebla es un elemento que se menciona durante toda la novela y tiene que ver con el estado sicológico de la protagonista. Bombal en su entrevista con Lucía Guerra-Cunningham habla sobre el significado de la niebla y dice que la niebla es la inmovilidad definitiva. "Es también algo como la 
incertidumbre, algo que anticipa una tragedia, lo funesto. Todos mis personajes comparten un destino trágico" (Entrevista 126).

Cedomil Goic considera la niebla algo ambiguo, "Puede considerarse también como un signo caracterizador de la incertidumbre con que el personaje se mueve entre la vigilia, el sueño y el ensueño, y, en general, como un signo de indeterminación de lo real. Una expresión, por último, del sentimiento metafísico de la inseguridad del hombre en el mundo"(184-185).

La niebla sirve como leitmotiv que crea una atmósfera onírica y de fantasía, de misterio, de pavor, que es un elemento surrealista que Bombal usa como una técnica en su obra. La niebla separa a la protagonista de la realidad externa y sirve como una cortina entre el mundo interior y emocional de la protagonista y su vida en el mundo externo y real.

Por ejemplo, su encuentro imaginario con su amante ocurre en una noche de niebla, "Entre la oscuridad y la niebla vislumbro una pequeña plaza. . . . La luz blanca de un farol, luz que la bruma transforma en baho, baña y empalidece mis manos, alarga a mis pies una silueta confusa, que es mi sombra. $Y$ he aquí que, de pronto, veo otra sombra junto a la mía" (Última 18). Margaret Campbell piensa que, "The characters cross from reality into fantasy on a bridge of dreams and day dreams. The approach to the bridge on the side of reality is made more accessible to them by the author's use of fog or mist,and rain" (417). 
Su segundo encuentro con el amante también ocurre en la niebla cuando está bañándose en el estanque, "Hoy he visto a mi amante. . . Sucedió este atardecer, cuando yo me bañaba en el estanque. ... Emergía de aquellas luminosas profundidades cuando divisé a lo lejos, entre la niebla, venir silencioso, como una aparición, un carruaje todo cerrado. . . se perdió de improviso en el bosque, como si se lo hubiera tragado la niebla" (Última 25-26). Vemos que la niebla transporta a la protagonista de la vida real a su mundo imaginario con el amante.

Alberto Rábago dice, “. . . ; la bruma externa es pararela a la niebla de confusión y negación existente en su alma" (36). La niebla es como un símbolo poético del estado emocional de la protagonista y como Campbell indica, “ . . the fog serves to create a poetic atmosphere for introspection" (417). La narradora misma dice, "La niebla, con su barrera de humo, prohibe toda visión directa de los seres y de las cosas, incita a aislarse dentro de sí mismo" (Última 39).

La niebla cubre todo y prohibe percibir la visión real de las cosas lo cual es un paralelo de la confusión interior de la protagonista. La niebla como una cortina cubre la realidad y por eso confunde a la protagonista entre lo real y lo soñado y como consecuencia de esto ella pierde su identidad. Al darse cuenta de ello trata de suicidarse. Es algo que dura sólo un instante: "El hecho de lanzarse bajo las ruedas de un vehículo requiere una especie de inconsciencia. Cerraré los ojos y trataré de no pensar durante un segundo. Dos manos que me parecen brutales me atraen 
vigorosamente hacia atrás" (Última 42). Son las manos de su esposo que le impiden el suicidio. Un hombre, que controla no sólo su vida, sino también su muerte.

Ella comprende que en una sociedad patriarcal la mujer está casi totalmente limitada. La mujer no tiene derecho a elegir su destino ni aún su muerte, 'El suicidio de una mujer casi vieja, qué cosa repugnante e inútil. ¿ ¿Mi vida no es acaso ya el comienzo de la muerte? . . Pero un destino implacable me ha robado hasta el derecho de buscar la muerte, ... " (Última 42-43).

Vemos que cuando ella está con Daniel o en su casa siempre está rodeada por la niebla que es un pararelo a su infelicidad y ya que la niebla también es una fuerza destructora y de inmovilidad infinita sirve de metáfora para la destrucción de su identidad. Al substituir a la difunta mujer de Daniel, ella ha perdido su propia identidad. Sentimos la opresión:

La niebla se estrecha, cada día más, contra la casa. Ya hizo desaparecer las araucarias cuyas ramas golpeaban la balaustrada de la terraza. Anoche soñé que, por entre rendijas de las puertas y ventanas, se infiltraba lentamente en la casa, en mi cuarto, y esfumaba el color de las paredes, los contornos de los muebles, y se entrelazaba a mis cabellos, y se me adhería al cuerpo y lo deshacía todo, todo ... Sólo en medio del desastre, quedaba intacto el rostro de Regina, con su mirada de fuego y sus labios llenos de secretos. (Última 16) 
La única cosa que la niebla no es capaz de destruir es la pasión y el amor de Regina por su amante lo cual “. . . indica el triunfo de la pasión y la vitalidad sobre un orden social que troncha en la mujer sus fuerzas instintivas" (Guerra-Cunningham, Narrativa 57). Continúa el "triángulo del deseo" propuesto por Girard, con Regina en el papel de mediadora. La protagonista en casa de su amante, sólo encuentra calor y pasión y aquí el poder destructivo de la niebla fracasa y la pasión gana contra la muerte y la destrucción de la niebla, "La noche y la niebla pueden aletear en vano contra los vidrios de la ventana, no conseguirán infiltrar en este cuarto un sólo átomo de muerte" (Última 19).

Durante toda la novela la bruma tiene una relación directa con el estado emocional de la protagonista, es decir cada vez que la tristeza y la desesperación sobre su vida y su matrimonio crecía, la niebla se estrechaba más y más contra la casa y borraba toda su vida, su juventud y su identidad. Cedomil Goic describe la niebla como, 'La función específica de la niebla es representar lo ominoso, la presencia de las potencias hostiles del mundo. . . la primera percepción de la niebla es la de una potencia enemiga que se suma a la del silencio y la muerte" (180-181).

En la novela de Mastretta también hay símbolos de la naturaleza que tienen relación con el estado emocional de la protagonista. Por ejemplo, vemos que a Catí le encanta el mar y es lo que la tranquiliza cuando se siente triste y necesita relajarse. Ella habla de la casa que compraron en la playa y dice, “Andrés compró una casa en Acapulco a la que no iba nunca porque el mar le parecía una pérdida del tiempo. Yo 
me la apropié. ... La casa quedaba entre Caleta y Caletilla, la rodeaba el mar y las tardes ahí se iban como un sueño. Hubiera podido pasarlas todas sentada en la terraza mirando al infinito como vieja empeñada en los recuerdos" (Arráncame 272).

El agua por su carácter calmante y símbolo de la vida y la fuerza primordial produce paz y bienestar en Catí. La protagonista de Bombal también describe su sentido de bienestar, 'Y entonces se produjo el milagro. Un murmullo leve, levísimo, empezó a mecerme, mientras una delicada frescura con olor a río se infiltraba en el cuarto. Era la primera lluvia de verano. . . Fuera crecía y se esparcía el murmullo de la lluvia, como si ésta multiplicara cada una de sus hebras de plata" (Última 30).

En otra ocasión también el agua es el motivo de su bienestar y como la niebla tiene una relación con el estado sicológico de la protagonista cuando dice, 'Y en el momento en que sentía cierto extraño nudo retorcerse en mi garganta hasta sofocarme, la lluvia empezaba a caer. Se apoderaba entonces de mí el mismo bienestar del primer día. Me parecía sentir el agua resbalar dulcemente a lo largo de mis sienes afiebradas y sobre mi pecho repleto de sollozos" (Última 31).

El milagro que la protagonista menciona es el cambio repentino de la actitud de su marido diciendo, "Sin embargo, todo fue imprevisto y tremendo y hay un vacío en mi memoria hasta el momento en que me descubrí, entre los brazos de mi marido" (Última 28). Este cambio se refleja con un cambio en la naturaleza, es decir que ahora en vez de la niebla vemos la presencia de la lluvia lo cual simboliza el renacimiento de una nueva etapa en el matrimonio de la protagonista. De esta manera, el agua como 
elemento primordial de la vida y símbolo de fecundidad representa una esperanza y oposición contra las fuerzas destructivas de la niebla. Vemos que al contrario de la niebla que simboliza la destrucción, la muerte y el silencio, el agua en forma de lluvia, río o mar se asocia con la vida y es un elemento positivo.

En Arráncame la vida, al contrario de Catalina que ama el mar, Andrés lo odia. Hablando de Acapulco dice, “- Acapulco. Ese horror sólo lo soportas tú. . . . No tengo tiempo para andar chapoteando y no descanso ahí. Me molesta el mar, no se calla nunca, parece mujer. A donde voy a irme es a Zacatlán. Ahí entre los cerros se descansa bien y los días duran tanto que da tiempo de todo" (Arráncame 287-288).

Se ve la diferencia entre el punto de vista de Catí y el de Andrés y el uso del mar como metáfora de la mujer que es un comentario machista. En lugar del mar que simboliza una infinidad de espacio y libertad, Andrés prefiere los cerros de Zacatlán. Los cerros por su tamaño son más controlables que el mar. Ya que Andrés siempre quiere estar en control de todo lo que lo rodea, el mar parece ser una amenaza para él.

Por otro lado, a Catí no le gusta la tierra de Andrés y no quiere volver allí y está contenta de que con la muerte de Andrés no volverá más a Zacatlán. Ella dice, "Detesto ese lugar tan mojado, tan lleno de recovecos, ..."(Arráncame 300). Para Catí ese lugar donde siempre llueve y no se ve el sol es algo deprimente y por eso el sol de Acapulco y el mar le gustan mucho porque se siente más contenta y su estado emocional cambia con el tiempo. 
Esta diferencia de gusto entre Catalina y Andrés sobre el mar y el cerro puede simbolizar sus personalidades. El mar como una forma de agua representa vida, alegría y actividad. Se relaciona con Catí que es una mujer activa y viva y con una personalidad abierta, amigable como el espacio abierto del mar. El mar también se asocia con la sal y eso en cuanto a la personalidad de Catalina se puede interpretar como la gracia, el salero, que vemos en su lenguaje y su actitud. Por ejemplo, una vez que Andrés le hace el amor brutalmente y después se pone a dormir Catí observándolo dice, 'Me levanté de un brinco. Me vestí en segundos. Carlos estaba afuera y yo ahí de estúpida contemplando al oso dormir" (Arráncame 224). Catalina a menudo, demuestra su sentido de humor y su lenguaje gracioso.

Por otro lado, el cerro con su espacio cerrado simboliza la matriz y la cuna y así representa un lugar de protección. La vuelta de Andrés a los cerros significa su vuelta a los brazos de la madre, donde efectivamente vive, $y$, es el lugar donde puede estar protegido y puede descansar sin preocuparse de los problemas del mundo exterior. También los cerros con su espacio cerrado representa a un Andrés reservado en sus relaciones con los demás, que guarda secretos y demuestra varias personalidades.

Debemos pensar también en las actividades diarias de ambos lo cual se relaciona con su gusto diferente entre mar y cerro. Andrés es una persona activa que siempre está fuera de casa ocupado con sus negocios. Por lo tanto, cuando quiere descansar le gusta estar en un lugar tranquilo donde no debe preocuparse por nada. Por otro lado, Catalina por tener una vida tranquila y acomodada, se cansa de estar en casa y quiere 
vida, acción y entretención y por eso le gusta la inquietud del mar y la alegría que le da el sol. No puede aguantar el cerro con su lluvia.

Para las dos protagonistas la naturaleza parece ser un refugio donde se sienten libre de las normas de la sociedad y también del espacio cerrado de la casa. Dice Lucía Guerra- Cunningham, "se destaca la presencia de una heroína cuya situación problemática residía en la inadecuación entre la esencia del ser femenino y los valores de una sociedad patriarcal" (Citada por Agosín, Silencio: 40). En la misma página, Agosín comenta, "obviamente, que esa esencia femenina se liga a la presencia del ámbito libre y natural en oposición a un ámbito cerrado.”

Este ámbito cerrado de la casa como símbolo del mundo de las convenciones es presentado desde el principio de la novela por los elementos de frío, lluvia, vendaval y la atmósfera inhóspita de la casa. Todos estos elementos representan el silencio, la muerte y la ausencia de amor que se oponen a la vida y muestra la indiferencia y la frialdad de la relación matrimonial de la protagonista con su marido (GuerraCunningham, Narrativa 59).

Esta idea está representada en la novela así, 'El vendaval de la noche anterior había removido las tejas de la vieja casa del campo. Cuando llegamos, la lluvia goteaba en todos los cuartos. . . Pasamos a una segunda habitación más fría aún que la primera" (Última 9-10)

También en la novela, la casa al contrario de su simbolismo tradicional de refugio y lugar protector es un espacio del cual la protagonista siempre quiere huir. 
Tiene miedo de la inmovilidad y el silencio que invaden la casa (Agosín, Apreciaciones 126). Asociando estos dos elementos con la muerte, ella compara la casa con una tumba y dice, "Desciendo la pequeña colina sobre la cual la casa está aislada entre cipreses, como una tumba, y me voy, a bosque traviesa, ... "(Última 12).

Esta asociación de casa y tumba puede extenderse un poco más ya que tradicionalmente la casa se asocia con el cuerpo. Consecuentemente, existe la conección de que el cuerpo de la protagonista es una tumba, con las ventanas cerradas hacia el mundo exterior. La vida de la protagonista, entonces, se reduce a una vida interna, la vida de los sueños. La casa que normalmente simboliza protección es para la esposa de Daniel una prisión, donde se siente sofocada (Última 17). La cocina, lugar de transformación, de cambio, de desarrollo (Cirlot 146) donde a menudo la mujer busca amparo frente a su situación no figura en la novela. Viene a enfatizar lo dicho. La narradora añade que es una "casa . . entre cipreses." El ciprés, como sabemos, es un árbol que se hermana con la tumba y el cementerio. Es una visión tétrica.

En varias ocasiones vemos que la protagonista de Bombal corre al bosque al sentirse sofocada. Por ejemplo, cuando ve a la muchacha muerta en el ataúd, "Atravieso casi corriendo el jardín, abro la verja. ... Esquivo siluetas de árboles, a tal punto estáticas, borrosas, que de pronto alargo la mano para convencerme de que existen realmente" (Última 12). Cuando ella se enfrenta con la muerte y la inmovilidad para asegurarse de su propia existencia se refugia en la naturaleza. 
También en la noche que encuentra a su amante se siente incapaz de respirar y el espacio cerrado de su cuarto la sofoca, "A medianoche me despierto, sofocada. ... Me ahogo. Respiro con la sensación de que me falta siempre un poco de aire para cada soplo. Salto del lecho, abro la ventana. . . La niebla, esfumando los ángulos, tamizando los ruidos, ha comunicado a la ciudad la tibia intimidad de un cuarto cerrado. . . . Me visto. . . . Echo a andar, calle arriba" (Última 17).

La narradora se escapa de su casa donde el espacio es limitado y se siente enjaulada hasta el punto de no poder respirar. Ella se siente sin identidad y casi muerta y el silencio que la rodea intensifica su miedo y su crisis. Bajo tal circunstancia, la naturaleza es el único lugar donde ella puede asegurarse de su existencia. Lucía Guerra-Cunningham habla del simbolismo de la casa en las obras de Bombal diciendo, “... se destaca el espacio cerrado de la casa como un símbolo de la regulación social que anula la naturaleza misma de la condición femenina en sus proyecciones inconscientes y como fuerza vital integrante de lo cósmico y primordial" (Narrativa 65$66)$.

Para Freud, la casa es símbolo de la personalidad humana en su sentido total (Fernández 113). Además, como hemos visto, la casa representa el cuerpo humano (Cirlot 146) y por eso al escaparse de la casa y correr al bosque, la narradora abandona su cuerpo o su personalidad y busca refugio en el bosque que simboliza el inconsciente y allí empieza a inventar su propio mundo imaginario. Según Jung, la mayoría de las 
veces, los sueños toman lugar en el bosque que representa el inconsciente y en un escenario ideal para las acciones imaginarias y oníricas (Citado por Fernández: 112).

Otra escena importante en la novela que se relaciona con la naturaleza y la encontramos en las dos novelas es la del baño en el estanque. En la novela de Bombal la protagonista después de enfrentarse con Regina y su amante besándose, otra vez se refugia en la naturaleza. Ella huye al bosque y para calmar este calor y pasión que ha surgido en ella se sumerge en el estanque. El agua como elemento primordial y con su frescura le da un sentido de bienestar y de alivio. En el sentido erótico substituye a su amante imaginario, "Tibias corrientes me acarician y penetran. Como con brazos de seda, las plantas acuáticas me enlazan el torso con sus largas raíces. Me besa la nuca y sube hasta mi frente el aliento fresco del agua" (Última 14-15).

El agua es vida y contiene el germen de otras vidas que ella no tiene es decir el hecho de no tener niños. Además, el agua purifica y simboliza el sentido de vida y la activación de la libido.

También el estanque como parte de la naturaleza es un lugar donde ella puede sentirse libre de las convenciones morales de la sociedad patriarcal hacia la mujer. En la naturaleza ella puede adornar y observar su cuerpo y darse cuenta de su belleza. Ella menciona esta sensación al sumergirse en el estanque, 'Y así, desnuda y dorada, me sumerjo en el estanque. No me sabía tan blanca y tan hermosa. El agua alarga mis formas, que toman proporciones irreales. Nunca me atreví antes a mirar mis senos; ahora los miro. Pequeños y redondos, parecen diminutas corolas suspendidas sobre el 
agua" (Última 14). En este sentido el estanque también sirve como espejo que presenta una imagen de consciencia y de revelación (Cirlot 168), una forma de poder vernos a nosotros mismos.

La inmersión en el agua “tibias corrientes” también representa una forma de expresar los sentidos pasionales y la sensualidad que la protagonista no puede mostrar dentro del espacio de la casa que representa el mundo de las convenciones sociales, “. . obliga a una existencia convencional bajo la cual se esconden anhelos e instintos que sólo encuentran expresión en el ámbito natural donde aún perdura la vitalidad" (Guerra-Cunningham, Narrativa 64).

Otro simbolismo de la inmersión en el agua es del retorno a lo preformal, con su doble sentido de muerte y disolución, pero también de renacimiento (Cirlot 345). La protagonista al sumergirse en el agua parece nacer de nuevo y gozar de los sentimientos y la belleza que nunca había experimentado antes y por primera vez ella expresa su pasión. Acerca de la inmersión en el agua y su simbolismo Jorge Rossi comenta, “. . . el agua quieta remite al reposo del origen, al refugio protector de la matriz licuescente. La inmersión de la protagonista . . reviste un carácter ceremonial y sagrado de retorno al útero materno" (Citado por Agosín, Apreciaciones: 226).

El estanque como un espacio hermético separa a la protagonista de la realidad que la rodea y es un lugar donde puede estar protegida de las fuerzas hostiles de la sociedad patriarcal (Agosín, Apreciaciones 226). Además el estanque al contrario del río y la lluvia que representan movimiento y cambio es una forma de agua que está 
inmovil. Esto en relación con la vida de la protagonista simboliza el aburrimiento y la repetición que existe en su vida cotidiana y eso se ve en el siguiente parráfo:

Mañana volveremos al campo. Pasado mañana iré a oír misa al pueblo, con mi suegra. Luego, durante el almuerzo, Daniel nos hablará de los trabajos de la hacienda. ... Después de comer me divertiré en provocar pequeñas catástrofes dentro del fuego, removiendo desatinadamente las brasas. A mi alrededor, un silencio indicará muy pronto que se ha agotado todo tema de conversación y Daniel ajustará ruidosamente las barras contra las puertas. Luego nos iremos a dormir. Y pasado mañana será lo mismo, y dentro de un año, y dentro de diez; . . . . (Última 18)

En la novela de Mastretta vemos que Catalina también usa el agua como parte de la naturaleza para escaparse de los problemas. Para refugiarse y estar sola consigo. Después de estar toda la noche con Carlos durante el día sólo quiere estar sola y en un lugar tranquilo donde pueda pensar en su amor por él y en un futuro juntos. Ella dice, 'El baño era mi rincón favorito, ahí me escapaba a estar sola. Esa mañana entré corriendo, abrí las llaves del agua y me desvestí aventando la ropa. Recuerdo mi cuerpo de entonces metido en "el agua caliente" [énfasis mío], entre las plantas, boca arriba, con la cabeza mojada y la cara fuera viendo pasar las nubes por el pedazo de cielo que cabía en los cristales del tragaluz" (Arráncame 195). 
Catí como la protagonista de Bombal se siente tranquila y segura en el agua observando las nubes y el cielo. Crea su mundo imaginario sin ningún obstáculo o convención. Esta escena "viendo pasar las nubes" tiene también una representación símbolica. Como menciona Levine, las nubes como otra forma de agua son símbolos de la indeterminación y la indecisión (Citada por Agosín, Apreciaciones: 140). Podemos interpretar este aspecto en relación con la vida de Catí a través de la figura de Carlos. Después de hacer el amor con Carlos, Catalina siente que su amor hacia él es tan fuerte que está dispuesta a dejar a Andrés. Esto quiere decir que por un lado ella quiere estar con Carlos y dejar todo el resto, su casa, sus niños y su general . Catalina muchas veces piensa en escaparse con Carlos pero tiene miedo de Andrés. Por otro lado, se ve que ella ya está costumbrada a una vida acomodada y le gusta su título de gobernadora. Podemos observar este sentimiento en el comentario de Catalina que sigue:

- ¿Y ahora qué hago? - dije, como si tuviera una confidente bañándose conmigo. Puedo salir corriendo. Dejar al general con todo y los hijos, la tina, las violetas, la cuenta de cheques que nunca se vacía - . Me quiero ir con Carlos - dije enjabonándome la cabeza - . Ahora mismo me voy. . . . Hoy me cambio de casa, duermo en otra cama y hasta de nombre me cambio. (195)

Es obvio que su manera de pensar y esa actitud de ser independiente es muy controversial con los roles tradicionales de la mujer en el patriarcado donde ese tipo de 
comportamiento se asocia con el hombre y es algo anormal en la mujer. A pesar de todo, ella no puede decidirse y eso se ve cuando habla con Carlos y dice:

Tengo treinta, quiero mandarme, quiero vivir contigo, ... Quiero que me lleves a Nueva York y que me presentes a tus amigos. Quiero que me saques del ropero y decirle todo al general Ascencio... . Cuando nos despedimos lo volví a recordar, casi me gustó tener que decirle que me iría cuatro días al encierro de Puebla, sin él, con mi marido, con mis hijos y mis sirvientes, a mi casa, mezcla de guardia y convento, llena de corredores y macetas, recovecos y fuentes. (Arráncame 204-205)

Otro elemento que tiene mucha importancia en la obra de Bombal es el simbolismo del pelo. Como menciona Bombal misma en una entrevista con Lucía Guerra-Cunningham, "Yo siempre he pensado que el pelo de la mujer es como las enredaderas, una prolongación de la naturaleza, el cabello las une a la naturaleza" (Entrevista 127). Podemos agregar que el cabello es una extensión del alma (Walker 367).

Esta relación entre la mujer y la naturaleza se rompe en la sociedad patriarcal que está basada en el culto masculino y el poder está en el hombre. Esta idea está presentada por la imagen del pelo de la protagonista que tiene que llevarlo atado después de su matrimonio con Daniel. Esto simboliza la represión de lo femenino, del espíritu de la mujer por las normas de la sociedad que no la dejan expresarse. 
Llevando el pelo como la primera mujer de Daniel es una forma de perder su identidad y permitir que su marido la fuerce a ser otra persona que ella nunca puede ser ya que para él su primera mujer era una mujer perfecta. Daniel no la quiere por lo que ella es sino sólo la puede querer como un substituto de su primera mujer. Bombal quiere mostrar por medio del uso del cabello, que la protagonista ha permitido su propia destrucción. Como menciona Guerra-Cunningham, la apretada trenza simboliza, “. . la represión de lo instintivo pasional en la institución del matrimonio" (Narrativa 57). Esto quiere decir que la primera mujer también, por llevar su pelo como una trenza apretada, fue como un objeto para Daniel. Consecuentemente, el cabello suelto sería falta de control, algo de mal agüero (Walker 368) y de no presentar la imagen de pulcritud propia a la clase alta.

Vemos que Regina siempre lleva su cabello suelto simbolizando la fuerza vital, la fertilidad y la alegría de vivir lo cual es el elemento animal de la naturaleza humana (Cirlot 129). Eso significa que cuando Regina tiene relación con su amante está llena de vida y de alegría porque él le da el amor que a ella le falta en su matrimonio. Regina, en el hospital, con el cabello cortado, representa el castigo que tiene que sufrir por su rebeldía.

La protagonista evoca el momento, antes de casarse, cuando tenía el derecho a elegir: 'Hubo un tiempo en que los llevé sueltos, casi hasta tocar el hombro. ... Mi marido me ha obligado después a recoger mis extravagantes cabellos; porque en todo 
debo esforzarme en imitar a su primera mujer, a su primera mujer que, según él, era una mujer perfecta" (Última 13).

También el color rojo del cabello simboliza la pasión y la fuerza primordial porque corresponde al elemento fuego como lo indica Cirlot. Según él los cabellos rojos tienen carácter demoníaco (130). Cuando la protagonista habla de su cabello menciona el color y el brillo de su pelo y dice, "Muy lacios y apegados a las sienes, brillaban como una seda fulgurante. . . Me miro al espejo atentamente y compruebo angustiada que mis cabellos han perdido ese leve tinte rojo que les comunicaba un extraño fulgor, cuando sacudía la cabeza. Mis cabellos se han oscurecido. Van a oscurecerse cada día más" (Última 13).

Consecuentemente, la pérdida del color rojo del pelo y el hecho de oscurecerse cada día ofrece un paralelo con su vida que va apagándose poco a poco. Al casarse con Daniel no sólo pierde su libertad e identidad como persona sino le faltan amor y vitalidad, y Bombal nos presenta esto por medio del cabello. Además, vemos que cuando ella está en el cuarto de su amante él trata de desatar sus cabellos: "Casi sin tocarme, me desata los cabellos y empieza a quitarme los vestidos" (Última 20). Hernán Vidal dice, “. . . una cabellera suelta o desordenada representaba el triunfo de lo <<institivo >>" ( Citado por Fernández: 109). El amante al desatar el cabello de la protagonista le da vida y alegría y le devuelve su libertad como persona y la quiere como ella es y no para substituir a otra persona; y de esta manera ella se siente amada y con identidad propia. Desatar el cabello también es desatar los deseos 
pasionales que han sido reprimidos en su matrimonio. El amante la respeta por ser mujer no como un individuo inferior al hombre a quien la puede siempre controlar.

Hay un paralelo en el caso del simbolismo del pelo entre la protagonista de Bombal y Catalina. La protagonista de Bombal menciona que, "Y antes que pierda su brillo y su violencia, no habrá nadie que diga que tengo lindo pelo" (Última 13). Es obvio que Daniel no presta ninguna atención a su esposa y no aprecia su belleza. Daniel usa el silencio, de ignorar a la persona con quien vive como arma de control. En cuanto al caso de Catalina se nota que Andrés por estar metido en sus asuntos políticos tampoco se daba cuenta de la belleza de Catalina y eso se ve en las palabras de Catí que dice, 'Un día en el desayuno Andrés descubrió que me había crecido el pelo y que su brillo era lo mejor que había visto en años, encontró que mis pies eran más lindos que los de cualquier japonesa, mis dientes de niña y mis labios de actriz" (Arráncame 164). Ambas autoras entonces ponen de relieve el deseo de toda mujer de ser amada como persona y no como un mueble.

El uso del espejo y su función simbólica en la obra de Bombal tiene importancia también. En general el espejo como el lago es simbólico de introspección y un reflejo de sí mismo. Vemos que durante la obra la protagonista se mira en el espejo en varias ocasiones y cada vez se da cuenta de la deterioración y el cambio de su cuerpo que está perdiendo su belleza. Podemos ver a otras personas, todo el tiempo, pero tenemos que recurrir al espejo para auto contemplarnos. El espejo sirve un propósito doble, físico y 
también espiritual (Cirlot 201). Es una especie de meditación, de especular, usando el significado medieval de espejo [speculum] (Julian 269).

En una ocasión menciona, "Me miro al espejo y me veo, definitivamente marcadas bajo los ojos, esas pequeñas arrugas que sólo me afluían, antes, al reír. Mi seno está perdiendo su redondez y consistencia de fruto verde. La carne se me apega a los huesos y ya no parezco delgada, sino angulosa" (Última 22).

Esta obsesividad con el cuerpo y el espejo viene de su dependencia a un hombre como el eje de su vida lo cual puede ser en la forma de marido o amante. Lagos-Pope citando a Judith Kegan Gardiner dice, 'Para la mujer, la sexualidad y el cuerpo son factores más importantes en su concepción de sí misma que para los hombres, ya que a ésta se la ha acostumbrado no sólo a verse a sí misma a través de su aparencia física, sino también a establecer una estrecha relación entre lo externo y su interioridad" (Citada por Agosín, Apreciaciones: 129). En otras palabras, el espejo confirma, no sólo, una visión de lo físico exterior sino, también es un reflejo de la vida interior.

La protagonista cree que para ser feliz y para obtener el amor de un hombre tiene que ser joven y bonita. En esta frase, poco después de casarse, ella lo confiesa diciendo, “. . . soy bella y feliz! Sí, ¡ feliz!, la felicidad no es más que tener un cuerpo joven y esbelto y ágil" (Última 12). Pronto se da cuenta, que para ser feliz se necesita más. La insatisfacción sexual en su matrimonio que menciona al principio de la novela, "A la mañana siguiente, cuando me despierto, hay a mi lado un surco vacío en el lecho" (Última 11). Así, su vida está basada en una existencia corporal y materializada por 
tener un cuerpo joven y bello. La frialdad de Daniel hacia ella en la noche de boda le hace sentirse desamada ya que su cuerpo es algo familiar para su marido. GuerraCunningham comenta que el surco vacío de la noche de boda simboliza, “... el egoísmo, la frialdad y el desamor" (Narrativa 48). Esta necesidad de ser amada y admirada provoca la invención del amante.

Como menciona Beth Miller, "The body is thus a sign, an indicator of a woman's being-in-the-world as an object valued for its erotic attraction and fertility" (286). Miller añade, "These narrators seek lovers not to affirm their right to erotic fulfillment but to assuage their fear of aging" (287). Phyllis Chesler comenta sobre el concepto del suicidio en las mujeres diciendo, “ . . 69 percent of attempted suicides in America are female ..." (48). Además, Chesler piensa, "Female suicide attempts are the assigned baring of the powerless throat, signals of ritual readiness for self-sacrifice. ... an essential act of resignation and hopelessness" (49).

Con la muerte de Regina, viene un examen de conciencia. Esto quiere decir que la protagonista tiene que pensar profundamente en su vida y en su futuro con un marido que no la ama; en este momento pierde su esperanza. Ella se da cuenta que su cuerpo ya está viejo y arrugado y no es capaz de amar. Al mismo tiempo, piensa que ni el suicidio le va salvar de su situación desesperada. No tendrá ninguna importancia y será algo inútil.

Chesler apunta que el suicidio es una forma de mostrar la necesidad del individuo de ser amado y sentirse necesario (18). Este concepto de ser amado es lo 
que falta en la vida de la protagonista de Bombal. Este sentimiento de ser inútil y rechazada por el marido es la razón de su actitud negativa hacia la vida que viene de perder su propia identidad como mujer y tratar de substituir a otra persona. Daniel por su parte contribuye a ese problema porque nunca la acepta por lo que es y no hay comunicación entre ellos como parejas. Daniel, quizás, pensando que su esposa debería estar feliz pues tiene todo lo que necesita, materialmente, ciego a las necesidades emocionales de ésta. Ellos sólo son dos individuos que viven juntos sin amor, sin afecto, sin pasión y sin deseo sexual. Bombal quiere mostrar el patriarcado de los años 30 cuando los sentimientos de la mujer no contaban para nada.

En las dos novelas hay um paralelo en que las dos protagonistas tienen relación sexual con su marido sólo como un deber. Ella describe su relación con Daniel como algo aburrido y mecánico y dice, "Mi segundo encuentro con Daniel fue idéntico al primero. El mismo anhelo sordo, el mismo abrazo desesperado, el mismo desengaño. Como la vez anterior, quedé tendida, humillada y jadeante" (Última 29). Ella no sólo no siente ningún placer sino que se siente humillada. En realidad a través de toda la obra vemos, en Daniel, a una persona hermética, sin vida, aparentemente incapaz de sentir ninguna pasión. Daniel no parece sentir placer aún en los contados momentos en que tiene relaciones íntimas con su esposa.

En el caso de Catalina vemos que después de tener una relación amorosa con Carlos, ella ya no tiene ningún interés en Andrés y su relación sexual con él es como la protagonista de Bombal, algo mecánico: "Quítate la ropa. Qué trabajo cuesta que tú te 
quites la ropa - dijo tirando de mis pantalones. Lo dejé hacer. Pensé en Pepa diciendo: En el matrimonio hay un momento en que tienes que cerrar los ojos y rezar un Ave María. Cerré los ojos y me puse a recordar el campo" (Arráncame 223).

En otra ocasión hablando de su relación con Andrés dice, “Volvía a mi casa de madrugada y durante semanas no abrí la puerta de mi cuarto. Sólo a veces, como quien visita a su abuelo, tomaba té con Andrés en las mañanas" (Arráncame 280). También en la novela de Bombal la protagonista describe su relación con su marido como indiferente y aburrida y eso se ve en la siguiente frase, "Noche a noche, Daniel se duerme a mi lado, indiferente como un hermano" (Última 22). Es obvio que en el caso de las dos protagonistas, ya no existe una relación, las dos sólo viven por el amor de otro hombre, "Lo abrigo [a Daniel] con indulgencia porque hace años, toda una larga noche, he vivido del calor de otro hombre" (Última 23).

Vemos que aunque las protagonistas no experimentan ningún placer sexual con sus maridos, ninguna de ellas dice algo o protesta contra el acto sexual. Ellas guardan silencio; sólo lo hacen como un acto mécanico. Es el deber de la mujer para satisfacer al marido. Este tema del silencio tiene mucha importancia en el análisis de estas dos novelas y las dos autoras lo usan como técnicas para expresar su opinión y para representar a las protagonistas.

Bombal y Mastretta a través del silencio expresan lo que no pueden decir con palabras, 'Women's silence, though sometimes signaling exclusion, can also be read as resistance, as a ritual of truth, as a keeping of silence about something, and as a refusal 
to enact a subordinate position" (Laurence 58). Acerca del lenguaje del silencio Agnes Gullón comenta, "El acto de callar indica la presencia latente de un lenguaje que, al no convertirse en hablar, retenido o inexpresado por alguna razón, cobra para el usuario un valor y una intensidad distintos de los que tiene el lenguaje no hablado" (4).

Antes de examinar el tema del silencio y analizar algunos ejemplos de las dos novelas, quiero primero hablar sobre el estilo femenino de escribir. María Luisa Bombal en una entrevista con Lucía Guerra-Cunningham hace un comentario sobre el estilo femenino y masculino de escribir y dice, “... el nuestro es un estilo menos áspero, menos realista; es un estilo más del corazón porque las mujeres somos sentimentales y no materialistas" (Entrevista 126). Guerra-Cunningham hablando de esto piensa que Bombal tiene un modo especialmente femenino de enfrentarse con la realidad circundante y dice, "Difiriendo del modo masculino racional y lógico que cataloga y define con un propósito pragmático y utilitario, las protagonistas bombalianas se relacionan con la realidad de una manera puramente sensual substituyendo el intelecto por el cuerpo ... " (Visión 94).

En la sociedad patriarcal que está basada en el poder del hombre, la mujer siempre ha tenido que adaptarse a las normas dominantes y expresar su opinión en una manera oculta y decir las cosas sin en realidad usar las palabras; es decir a través del silencio. Como comenta Julia Kristeva, “Apartadas y enajenadas del lenguaje, las mujeres son visionarias bailarinas que sufren cuando hablan" (Citada por GuerraCunningham, Estrategias: 116). 
Dorothy Smith considera la participación de la mujer en la conversación como la relación entre los jugadores en un partido de fútbol y lo describe así:

Es como un juego en el cual hay más espectadores que jugadores. Algunos están ocupados en lanzarse una pelota entre ellos. Otros cumplen los roles de público y defensores, que recogen la pelota si ésta cae y la devuelven a los jugadores: ellos ayudan, facilitan y alientan, pero su acción no llega a ser parte del juego. En situaciones ordinarias de reunión y trabajo en conjunto, podemos encontrar estos mismos modelos. Lo que las mujeres tienen que decir, puede simplemente permanecer en el silencio. O puede ser tomado como algo divertido jamás integrado realmente al juego. Si llega a entrar a éste, es gracias a que un jugador masculino lo ha tomado y lo ha integrado como suyo.

Por estas razones vemos que en los textos de mujeres hay censuras y expresan opiniones apropiadas para su época. Por ejemplo, en la obra de Bombal vemos que cuando ella quiere expresar la unión sexual entre la protagonista y su amante, no usa palabras acerca del sexo sino que lo describe a través del uso de métaforas. Luego, cuando la protagonista se inmerge en el estanque, la descripción de las plantas que tocan y acarician su cuerpo se interpreta como un acto de masturbación que Bombal lo presenta con los símbolos de la naturaleza en vez de usar palabras directas (Rábago 36). 
En cambio, en la novela de Mastretta que es de una época más reciente vemos que cuando Catalina tiene sexo por primera vez con Andrés describe todo con detalles lo que no era posible en la época de Bombal. Existe, además, otro elemento; Catalina y Andrés pertenecen al pueblo. La protagonista de Bombal es de la clase acomodada por lo cual, no debía expresar sentimientos íntimos abiertamente. Lucía Guerra-Cunnigham menciona, "Atrapada, entonces, por un condicionamiento social y por modos literarios de representación, la mujer escritora tradicionalmente se autocensura recurriendo al silencio o al eufemismo, ... "'(Visión 89).

Entonces, el silencio y la imaginación son dos elementos que la mujer usa como armas. Tamara Kamenzain apunta, 'Ta mujer siempre ha estado más cerca del silencio que de la escritura porque su acceso al habla siempre ha sido marginal" (Citada por Agosín: Silencio 15). Esto quiere decir que el mundo exterior está controlado por el hombre donde la mujer no tiene un lugar propio y como resultado se refugia en el mundo interior de fantasía y sueño. Como Lagos-Pope señala hablando de las protagonistas de Bombal, “. . . esta tensión que viven los personajes femeninos corresponde a una realidad interior que no desafia el orden social. . . . el conflicto de la mujer se libra allí, no en el terreno social" (Citada por Agosín, Apreciaciones: 122).

El silencio es una manera para la mujer de concentrarse en el mundo interior y en la imaginación donde se puede decir todo sin temer los límites y las normas de la sociedad patriarcal donde todo está basado a favor del hombre. Luce Irigaray afirma, "I am trying ... to go back through the masculine imaginary, to interpret the way it 
has reduced us to silence, to muteness or mimicry, and I am attending, from that starting-point and at the same time, to (re)discover a possible space for the femenine" (164).

Irigaray continúa su definición del espacio para la mujer diciendo, "That is why it is very important for women to be able to join together, and to join together 'among themselves.' In order to begin to escape from the spaces, roles, and gestures that they have been assigned and taught by the society of men" (164).

En las dos novelas, el silencio es un elemento importante y en la novela de Bombal vemos que la protagonista usa la palabra "silencio" durante toda la obra. Sepúlveda-Pulvirenti dice lo siguiente, 'Las mujeres en las obras de María Luisa Bombal viven en medio de un gran silencio, silencio que las aleja del mundo de los otros y, al mismo tiempo, les da la posibilidad de crear una existencia dentro de sus propios espacios" (Citada por Agosín, Apreciaciones: 230). Por ejemplo, al principio de la novela cuando ella se enfrenta con la muchacha muerta por primera vez dice, "Esta muerta, sobre la cual no se me ocurriría inclinarme para llamarla porque parece que no hubiera vivido nunca, me sugiere de pronto la palabra silencio. Silencio, un gran silencio, un silencio de años, de siglos, un silencio aterrador que empieza a crecer en el cuarto y dentro de mi cabeza. . . alcanzo la puerta, después de haber tropezado con horribles coronas de flores artificiales" (Última 12). Estas flores artificiales enfatizan la falta de vida y también algo irónico, fuera de lugar, en una región donde abundan las flores. 
El silencio aquí es un signo de la muerte, de una vida sin amor y una muerte en vida. Ella tiene miedo porque no quiere morir y no quiere aceptar la realidad de su vida. Guerra-Cunningham apunta, “ . . la opresión de los espacios cerrados del ataúd y de la casa, la oscuridad de los trajes enlutados y la aridez de las flores artificiales" todos son elementos que ponen un énfasis en la inmovilidad y el silencio que rodean a la protagonista (Narrativa 54). Para asegurarse de que ella está viva y para escapar de este silencio, se refugia en la naturaleza, "Atravieso casi corriendo el jardín, abro la verja. Pero, afuera, una sutil neblina ha diluido el paisaje y el silencio es aún más inmenso....Y porque me ataca por vez primera, reacciono violentamente contra el asalto de la niebla" (Última 12). La escena de la muchacha muerta es un anuncio metafórico de su propia existencia futura.

Obviamente, parece que la naturaleza tampoco puede calmar su miedo de la muerte y de la inmovilidad. En la naturaleza también hay otros elementos que se relacionan con la muerte y le asustan: el silencio y la niebla. Además, su enfrentamiento con la niebla por primera vez es una nueva experiencia para ella y por eso no sabe como reaccionar.

María Luisa Bombal misma explica la importancia de esta escena diciendo, "La joven muerta no tiene nada que ver con la primera esposa de Daniel, es importante porque, por primera vez, mi protagonista ve una persona muerta, conoce la muerte ... y así, la niebla también la ataca por primera vez" (Guerra-Cunningham, Narrativa 54). La protagonista para romper este silencio que es un signo de la muerte contra la vida 
trata de despertar un eco pisando las hojas, “. ., y me voy, a bosque traviesa, pisando firme y fuerte, para despertar un eco. Sin embargo, todo continúa mudo y mi pie arrastra hojas caídas que no crujen porque están húmedas y como en descomposición" (Última 12).

Las hojas húmedas y silenciosas representan la muerte de lo que estuvo vivo y ahora está en descomposición y sin vida (Guerra-Cunningham, Narrativa 62). De esta manera la inmovilidad de la muchacha muerta se ha traspasado a la naturaleza y así no puede ser un refugio para ella. A esto se añade el asalto de la niebla. El silencio como la niebla es un símbolo de ambiguedad e inseguridad. Ella está confundida con su vida y destino porque su identidad ha sido robada por el marido y tiene que transformarse en otra persona para ayudar a su esposo en el dolor y sufrimiento. Además, el silencio es también el producto de la incomunicación que existe entre ella y su marido (Agosín, Apreciaciones 232). En muchas ocasiones podemos ver este silencio que existe entre ellos. Por ejemplo, a la hora de comer cuando Daniel le habla sobre el porvenir de las hermanas solteronas de la protagonista, ella no dice nada, "Comemos sin hablar. . . . Permanezco muda" y cuando oye el llanto de su marido, "Lo dejo pasar al cuarto contiguo sin esbozar un gesto hacia él, sin balbucir una palabra . . . (Última 10-11). O sea la protagonista no demuestra compasión por su esposo. Esto debido a que ella misma ha llegado a un estado alto de insensibilidad.

Cuando se enfrenta con Regina y su amante, guarda silencio, "Me voy sin haber despegado los labios" (Última 13). Cuando Regina protesta contra el capricho de su 
marido y de Daniel, de ir de caza, la protagonista otra vez reacciona con el silencio, "No le contesto,..." (Última 15). La protagonista prefiere estar callada, sola, con sus pensamientos, porque cree que su respuesta no será aceptada por Regina. Parece que Regina no cuenta mucho con las ideas de la protagonista quien explica la razón de su silencio continuando, “. . ., temiendo exasperarla con lo que ella llama mi candor” (Última 15). Candor es ingenuidad y es lógico entonces que ella prefiera no decir nada.

El uso de los sonidos durante la novela también intensifica la presencia del silencio (Agosín, Apreciaciones 233). Por ejemplo, al entrar a la casa del amante dice, “... nuestros pasos resuenan en cuartos vacíos. . . Oigo pasos muy leves sobre la alfombra de pies descalzos" (Última 19). Se ve que la invasión del silencio es tan fuerte que hasta los sonidos muy leves que normalmente no se oyen atraen la atención de la protagonista.

Mientras el silencio invade todo, la protagonista se ensimisma en su propio silencio y empieza a escuchar los sonidos eróticos al tocar el cuerpo de su amante (Agosín, Apreciaciones 233). La escena se describe de la manera siguiente, 'Lo abrazo fuertemente y con todos mis sentidos escucho. Escucho nacer, volar y recaer su soplo; escucho el estallido que el corazón repite incansable . . , transformando cada célula en un eco sonoro" (Última 20).

Sepúlveda-Pulvirenti interpreta esta escena como una comunicación silenciosa entre los amantes diciendo, "Se produce en este encuentro la verdadera comunicación 
que ella esperaba. Hay que hacer notar que esta comunicación fue lograda en el mundo del silencio que ha creado la mujer para escaparse del silencio ahogante de la incomunicación. ... Desde el momento en que crea la realidad del amante, vive la comunicación dentro del silencio" (Citada por Agosín, Apreciaciones: 233). Nos recuerda a San Juan de la Cruz con su "música callada" y "soledad sonora."

Una manera de comunicarse con el amante en silencio es a través de cartas, sueños y hablándole dentro de su imaginación y todo esto es posible sin decir ni una palabra. Rita Gnutzmann hace este comentario, "María Luisa Bombal, ..., describe el mundo del latifundismo patriarcal . . y plasma la situación de la mujer desocupada, reducida al hogar. La única forma de liberación del mundo banal es el refugio en los sueños y en la escritura" (93).

Cada vez que ella extraña a su amante o quiere comunicarse con él le escribe, 'Me levanto, enciendo a hurtadillas una lámpara y escribo: $<<$ He conocido el perfume de tu hombro y desde ese día soy tuya. Te deseo... . > "(Última 23). Luego continúa, 'Hoy he visto a mi amante. No me canso de pensarlo, de repetirlo en voz alta. Necesito escribir: ... (Última 25). En otra ocasión cuando tiene relación sexual con Daniel, se siente culpable por haber engañado a su amante y otra vez trata de escribir para confesarlo, 'Le escribo para disipar un naciente malentendido: $<<$ Yo nunca te he engañado. . . . \" (Última 29). Lagos-Pope cita a Lawrence Lipking quien afirma que, "la mujer que lee y escribe implícitamente desafia el silencio" (Citada por Agosín, Apreciaciones: 123). Agosín explica este punto diciendo, “. . , un 
desafio para atreverse a decir lo mucho que se sabe decir y a la rebeldía del mismo silencio impuesto por un orden jerárquico" (Silencio 18).

En otra ocasión Agosín continúa su comentario acerca de la escritura diciendo, "Escribir, ..., implica la salida del encierro y el adentramiento hacia un texto que se niega al silencio, que hace posible la exterioridad del sonido. La escritura . . . responde al hábito de la mujer de elaborar urdimbres por medio de la imaginación. Es una vía utópica para la libertad y la fantasía ilusionada, ... "(Escritura 118). Al escribir la mujer reaparece, es un renacer y de descubrirse a sí misma. Sorprendente es el comentario de Simone de Beauvoir: "One is not born, one becomes, A Woman" (Felman 12).

Como he mencionado ya, otra forma que la protagonista de Bombal usa para comunicarse es a través del sueño y dice, "Mi único anhelo es estar sola para poder soñar, soñar a mis anchas" (Última 23). El sueño le sirve para cumplir sus deseos: reunirse con su amante y hablarle. Este mutismo llega a un punto que aun cuando cree que ha visto a su amante no le puede hablar y las palabras no salen de su boca, "Quise llamarlo, pero mi impulso se quebró en una especie de grito ronco, indescriptible. No podía llamarlo, no sabía su nombre" (Última 26). Tenemos que recordar que en su primer encuentro con el amante no existieron ni palabras ni voz y por eso no sabe su nombre. Aunque ella no se da cuenta de eso, Daniel le hace entender que el amante fue sólo una ilusión porque ella no puede recordar su voz. 
Cuando la protagonista pierde la esperanza de ver a su amante algún día, otra vez, regresa al silencio de la incomunicación que existe entre ella y Daniel (Agosín, Apreciaciones 234). Esta incomunicación se expresa en esta frase que dice, "Daniel volvió a extenderse a mi lado y largas horas permanecimos silenciosos, ... " (Última $30)$.

Al final de la novela cuando al regreso a la ciudad está convencida que su amante fue sólo un sueño, el silencio la domina. Ella decide no luchar más por un verdadero amor y se resigna a una vida de silencio (Agosín, Apreciaciones 234), "Me dejo caer sobre un banco para que se haga por fin, el silencio en el universo y dentro de mí" (Última 39).

El silencio en la obra de Bombal también existe en la forma de espacio en el texto como una técnica narrativa de la autora. No hay capítulos o partes que dividan la obra, pero hay espacios en blanco y pausas que significa el pasar del tiempo (Agosín, Apreciaciones 235). También al final de las frases aunque las palabras terminan, hay puntuaciones que indican que la narración todavía continúa. Laurence explica el uso de estos espacios narrativos diciendo, "These narrative spaces are created in silent dialogue with the reader, who is expected to assume the same active and insightful position as the silent, observing female character in fiction" (59).

Por ejemplo, la protagonista de Bombal como un personaje silencioso dice, "Me basta saber que existe, que siente y recuerda en algún rincón del mundo ... " (Última 23). Laurence piensa que las elipses nos invitan a leer lo que no está escrito es decir 
el silencio en el texto (107). Según Sepúlveda-Pulvirenti, 'Esto sirve para profundizar la sensación de que con lo que se calla también se dice. Se da así gran dramatismo a la desesperación de la protagonista, pero más que nada, sirve como extensión del gran silencio que invade el mundo de la mujer" (Citada por Agosín, Apreciaciones: 235).

En la obra de Mastretta el silencio está presente en diferentes formas y por diferentes personajes como una estrategia para ganar lo que quieren. Catalina tiene una relación muy estrecha con su padre; es una relación paralela a la relación de la autora misma con su padre, "I was born and raised in Puebla . . . I worshiped my father, who died when I was very young" (Beer 14). En el caso de Catalina esta relación no parece auténtica. Cada vez que Catalina tiene un problema y quiere hablar, su padre trata de cambiar el tema de la conversación y quiere hablar de otras cosas tratando a Catalina como a una niña.

Otra razón, que explica el comportamiento del padre puede ser que él cambia el tema de la conversación para que Catalina se olvide de sus problemas y se sienta mejor. Por ejemplo, se nota que, normalmente a Catalina no le importa la opinión de la gente y hace lo que le da la gana pero en el caso de su nuevo estilo de pelo le preocupa la opinión de los amigos de Andrés. Al contarle a su padre su depresión, se ve que él trata de cambiar el tema de la conversación y distraerla diciendo, "Venga mi vida, venga que le preparo uno con mucha azúcar, venga cuéntele a su papá. Por supuesto no le contaba yo nada. El no quería que yo le contara, por eso se ponía a hablarme 
como a una niña que no debía crecer y terminábamos abrazados mirando los volcanes, agradecidos de tenerlos enfrente y de estar vivos para mirarlos" (Arráncame 76).

El padre no quiere aceptar que su hija ya no es una niña sino que es la esposa de un político, con problemas y, quiere discutir estos problemas con su padre (Bailey 136137). Vemos que el padre al silenciar a Catalina trata de hacerla olvidar de sus problemas. Parece que para él hablar de problemas sólo crea más líos y es mejor olvidarlos. Podemos decir que esta es una forma del padre para demostrar su amor por Catalina porque quiere protejerla del dolor y sufrimiento emocional. Además, el padre por ser tradicional puede creer que Catalina como esposa tiene que obedecer a su marido y por tener una vida acomodada no tiene que quejarse de nada. Le dice, “ ¿No tienes todo lo que quieres? No llores" (Arráncame76). El padre demuestra su sabiduría no interviniendo directamente. Sin embargo, son los consejos de una generación anterior que la nueva generación nunca acepta. Además, sabe que si le da consejos puede crear aun más problemas; Andrés podría interpretar todo eso como interferencia.

En el caso de Andrés podemos ver durante toda la novela muchas ocasiones donde el silencio y falta de comunicación causa problemas y sorpresas entre él y Catalina. Por ejemplo, Andrés nunca habla con Catalina sobre su vida personal y sus otras relaciones, Catalina no sabe nada de las otras mujeres y los niños que él tiene (Bailey 138). Un día Andrés llega a casa con sus dos niños Octavio y Virginia y le dice a Catalina que iban a vivir con ellos. Catalina ya sabía que iban a haber otras sorpresas 
y dice, "Supe que tenía otras hijas hasta que le cayó la gubernatura. Entonces consideró necesario ser un buen padre y se me presentó con cuatro más" (Arráncame 56).

En otra ocasión vemos que Andrés engaña a Catalina con su silencio cuando se da cuenta de que a Catalina le gusta Fernando Arizmendi porque sabe que él es homosexual y no tiene que preocuparse (Bailey 138). El comenta con su secretario, “- No cabe duda que los maricones son fuente de inspiración - . A las mujeres les encanta platicar con ellos. Quién sabe qué tienen que les resultan atractivos. Con decirte que cuando conocimos a éste yo hasta me puse celoso y encerré a Catalina. Ahora es el único novio que le permito y me encanta ese noviazgo" (Arráncame 107).

Hasta ahora Catalina pensaba que estaba engañando a Andrés. Al final, en el caso de la muerte de Carlos, fue Catalina quien fue engañada con el silencio. Catalina piensa: “. ., era como un espía invisible pero siempre tras la puerta sabiendo todo" (Arráncame 154).

El silencio más trágico de la novela es el de Andrés acerca de la relación entre Catalina y Carlos (Bailey 138). El disimula que no sabe nada sobre esa relación y hasta a veces insiste que Carlos se siente al lado de Catalina en la mesa y lo invita a su casa sin decirle a Catalina, "Iba yo a decir alguna cosa para contradecirlos cuando entró Vives. ... - ¿Tú lo invitaste? - pregunté. - No te dije para darte la sorpresa - dijo Andrés. - Me la das - contesté -" (Arráncame 168). 
Se ve que Andrés tiene una buena táctica para sacar información sin preguntar directamente y les da la oportunidad para que estén juntos pero en el fondo su plan es asegurarse del adulterio de Catalina y terminarlo. Catalina y Carlos al estar enamorados pierden noción de la realidad. Se reunen en diferentes sitios pensando que Andrés no sabe nada. Este, en cambio, sólo espera al momento oportuno para atacar. $\mathrm{Al}$ enfrentarse con Catalina, Andrés rompe su silencio diciendo:

- Es increíble lo bien que sigues estando. Con razón traes a Carlos hecho un pendejo. - Carlos es mi amigo... . - Yo no cojo con Carlos dije mirándole a los ojos. - Está bien saberlo - me contestó y se puso a besarme $-\ldots .$. ¿No coges con Carlos? ¿Y qué estabas haciendo cuando te manchaste el cuerpo de amarillo? - me preguntó. - Rodar sobre las flores. . . . Eres mi mujer. No se te olvide - dijo después, ... (Arráncame 222-223)

Vemos que al final Andrés mata a Carlos algo que Catalina siempre había temido. Para Andrés, Carlos pasa de ser un amigo a un rival. Andrés está celoso porque verdaderamente ama a Catalina. Quizás no sentía eso por ella al principio.

Es obvio que todo el pueblo sabe quien asesinó a Carlos pero otra vez el silencio es la única opción. Andrés por su actitud machista y por ser un político poderoso para quien matar es parte de su trabajo, se ha creado una imagen horrorosa. Esta es la razón por la cual la gente e incluso Catalina guardan silencio, 'Yo preferí no saber qué hacía Andrés" (Arráncame 72). 
Hay algunas ocasiones donde ella no puede negar la realidad más y tiene que admitir la verdad sobre los asuntos de Andrés (Bailey 139). Por ejemplo, al oír algunas acusaciones contra Andrés Catalina lo defiende confesando, "Mi marido mata por negocios, no va por ahí matando a mujeres que no se dejan coger" (Arráncame 200).

Otra forma que Andrés usa para silenciar a Catalina es a través del sexo (Bailey 136). Catalina está muy curiosa sobre la muerte de un hombre que hacía negocios con Andrés, pero se ve que Andrés no está interesado en hablar de este asunto. Al contrario, su respuesta es tener sexo con Catalina brutalmente lo que es obvio en el siguiente comentario, "Quítate ese vestido que pareces cuervo, déjame verte las chichis, odio que te abroches como monja. Andale, no estés de púdica que no te queda. Me trepó el vestido y yo apreté las piernas. Su cuerpo encima me enterraba los broches del liguero" (Arráncame 98-99).

El silencio mayor y también trágico de Catalina fue el que causó la muerte de Andrés (Bailey 141). Al no decir nada acerca de los peligros del té de hierbas, Catí, a propósito, causa la muerte de Andrés. Este hecho es aparente en el siguiente comentario de Catalina sobre el té, “El té de esas hojas daba fuerzas pero hacía costumbre, y había que tenerle cuidado porque tomado todos los días curaba de momento pero a la larga mataba" (258).

Se ve que aunque Catalina no puede prevenirse de los actos violentos de Andrés y decir lo que piensa, usa su poder y su venganza es de manera silenciosa. Ese silencio de Catí, es un paralelo al silencio de Andrés cuando mató a Carlos y Catí lo 
sabía. Parece que durante la novela Catí aprende bastante de Andrés. Al morir éste vemos que la alumna salió más aventajada.

Mastretta con su novela quiere romper el silencio de la mujer mexicana. A través del personaje de Catalina ella crea su propia oportunidad de hablar y de criticar a la sociedad patriarcal mexicana y bregar por los derechos de la mujer (Bailey 141). Su punto de vista es el de la esposa de un cacique que cuenta la realidad de la vida de un político y los actos crueles y la corrupción que lo rodea.

El silencio entre Catalina y Andrés resulta en una falta de comunicación entre ellos y como Andrés mismo confiesa al final de la novela cuando está muriendo, “¿Tú qué quieres? Nunca he podido saber qué quieres tú. Tampoco dediqué mucho tiempo a pensar en eso, ..." (Arráncame 288). La pregunta de Andrés es una pregunta vital, que el hombre, generalmente, no se hace. La misma pregunta se podría haber hecho Daniel.

Felman explica que Freud fue la primera persona que hizo esta pregunta, "The great question, the great question that has never been answered and which I have not been able to answer, despite my thirty years of research into the feminine soul, is 'what does a woman want"' (Citado por Felman: 73). Felman apunta que lo que la mujer quiere no tiene mucha importancia en el sistema patriarcal, “. . . what a woman really wants is something altogether different than what patriarchy prescribes for her, assumes to be her 'natural' desire: otherwise, there is no room for such a question" (73). 
Creo que no existe una sola respuesta para esta pregunta porque lo que cada mujer quiere depende de su situación y la vida que lleva. Como dice Freud, "If you want to know more about femininity, enquire from your own experiences of life, . . " (Citado por Felman: 74).

En el caso de las protagonistas de Bombal y Mastretta, vemos que lo que la protagonista de Bombal quiere es amor y pasión en su matrimonio. Por otro lado, Catalina quiere tener su libertad y su independencia y quiere ser tratada como una persona y no sólo un objeto como "parte de la decoración." Por lo tanto, la respuesta a la pregunta que le hace Andrés a Catí, va a variar porque lo que quería Catí cuando se casó no es lo mismo de lo que quiere ahora o lo que querrá mañama. El deseo es un apetito en continuo movimiento (Felman 48-49).

Como menciona Anderson, "All of the political contradictions of the period, the class conflicts, and the social roles traditionally assigned to women in this historical and cultural context come to intersect in the figure of the governor's wife" (16).

Como he mencionado antes Catalina es una mujer fuerte que no quiere aceptar el rol tradicional de la mujer como madre o esposa fiel. En sus charlas con sus amigas lo menciona. Siendo la esposa del gobernador ella madura durante la novela y quiere participar en los asuntos políticos de Andrés. Siente aburrimiento de ser ama de casa: Me gustaría ser gobernadora. Llevaba casi cinco años entre la cocina, la chichi y los pañales. Me aburría. . . . , resolví cerrar el capítulo del amor maternal. Se los dejé a Lucina. . . . De un día para otro dejé de pasar las 
tardes con ellos, dejé de pensar en qué merendarían y en cómo entretenerlos. ... Se fueron acostumbrando y yo también. En cambio me propuse conocer los negocios de Andrés en Atenciego. (Arráncame 55,88- 89)

Mastretta con su novela quiere proponer otro rol y oportunidad para la mujer y librarla de los estereotipos de la sociedad patriarcal y dice, "I believe that in a certain way many of the women in Arráncame la vida . . are ahead of their time. They are women closer to us than to those of the thirties. . . What I am sure of is that in those years there were women who thought and lived the way we do" (Beer 16).

Catalina piensa en la igualdad de los derechos para la mujer y hombre. Por ejemplo, cuando ella se da cuenta de la infidelidad de Andrés, ella también empieza a tener relaciones fuera del matrimonio. Hay una relación entre los valores sociales de la novela y los valores de los aztecas. Por ejemplo, cuando una muchacha azteca se casaba, pasaba del control de su padre a su esposo y tenía que ser obediente en todo (Guerra-Cunningham, Mujer 9). Eso se ve en la novela de Mastretta que desde principio de su casamiento Catí tiene que obedecer a Andrés en todo lo que quiere. Como he mencionado antes, él ni siquiera le preguntaba a ella que si quiere casarse con él sino que un día lleva a toda la familia y dice que se iba a casar con Catalina. Andrés, al principio de su matrimonio trata de controlar todo:

- Yo quiero jugo de naranja - dije. - Usted se toma su café y su chocolate como todo el mundo. No meta el desorden - regañó Andrés 
... - Papá, dile que yo tomo jugo en las mañanas - pedí. - Tráigale un jugo de naranja a la niña - dijo mi papá . . La vida con un militar no es fácil. De una vez velo sabiendo. Y usted don Marcos, acuérdese que ella ya no es su niña y que en esta mesa mando yo. (Arráncame 21)

Ferdinand Anton agrega lo siguiente:

... la mujer no tenía los mismos derechos que el hombre. De ella se exigia virginidad antes del matrimonio y absoluta fidelidad matrimonial, mandamiento que no regía para el hombre. Entre los aztecas, según la ley, la infidelidad estaba castigada con la pena de muerte por lapidación. El mismo castigo estaba previsto para el esposo, pero al parecer sólo <<sobre el papel $\gg$. (Citado por Guerra-Cunningham, Mujer: 9)

En la novela vemos que Andrés piensa lo mismo y cuando se da cuenta de que a Catalina le gusta Fernando Arizmendi se pone furioso. Catalina le dice que él hace lo mismo y no tiene que estar enojado, pero Andrés le contesta que para él no es algo malo porque él es un hombre y puede ser infiel pero, “. . . las mujeres cuando andan de cabras locas queriéndose coger a todo el que les pone a temblar el ombligo se llaman putas" (Arráncame 102).

Con la figura de Catalina, Mastretta quiere presentar a la mujer de hoy y el cambio que ha ocurrido. Andrés hace un contraste:

Son un desastre las mujeres, uno se pasa la vida educándolas, explicándoles, y apenas pasa un loro junto a ellas y le creen todo. . . . 
Con tal de estar en contra de su marido. Porque ésa es su nueva moda. La hubieran conocido ustedes a los dieciséis años, entonces sí era una cosa linda, una esponja que lo escuchaba todo con atención, era incapaz de juzgar mal a su marido y de no estar en su cama a las tres de la mañana. Ah, las mujeres. No cabe duda que ya no son las mismas. Algo las perturbó. Ojalá y la suya se conserve como hasta ahora, diputado, ya no hay de ésas. Ahora hasta las que parecían más quietas respingan. Hay que ver a la mía. (Arráncame 218)

Es obvio que Catalina ha cambiado de ser una muchacha inocente y obediente a ser una mujer madura y agresiva. Esta agresividad no es algo común para una mujer y Catalina de esta manera rompe el estereotipo, lo cual, en realidad, Andrés admira. Se ve que este cambio, en la personalidad de Catalina, también crea un cambio en la personalidad de Andrés. Esto quiere decir que su opinión ya cuenta para algo, “. . . hablaba conmigo como con las paredes, sin esperar que le contestara, sin pedir mi opinión, urgido sólo de audiencia. . . . Hace cuatro días que hablas de lo mismo, ya me dio tiempo de tener una opinión.- Vaya con la señorita. No sabe ni cómo se hacen los niños y ya quiere dirigir generales. Me está gustando - dijo" (Arráncame 13). Anderson comentando la novela de Mastretta dice:

On the one hand, the story of her marriage displaces the prescribed social script for a proper wife and instead produces a bildungsroman of political and sentimental growth and cultural resistance. On the other 
hand, Cati's linguistic behavior underscores the dominant cultural ideals that would codify her access to language. (22)

A Andrés le gusta cuando ve que Catalina es diferente a las otras mujeres que son pasivas y nunca tienen su propia opinión. Andrés empieza a compartir sus asuntos políticos con Catí y pedir su opinión porque se da cuenta de su astucia:

Eres una vieja chingona. Aprendiste bien. Ya puedes dedicarte a la política. . . . Inventó nombrarme su secretaria privada . . . Dos días antes me hubiera hecho feliz. No sólo tener de nuevo su explosiva presencia, sino estar invitada a todo lo que tuve prohibido: a las reuniones y los acuerdos que siempre rehice tras la puerta, ... Entonces pude presenciarlos todos, si se me hubiera ocurrido opinar me habrían dejado". (Arráncame 121,163)

Este es un gran cambio para Catalina que al principio de la novela dice, "Oía sus instrucciones como las de un dios. Siempre me sorprendía con algo y le daban risa mis ignorancias" (Arráncame 24-25). En el final de la novela cuando Andrés está muriendo confiesa su admiración por Catí, “- No me equivoqué contigo, eres lista como tú sola, pareces hombre, por eso te perdono que andes de libertina. Contigo sí me chingué. Eres mi mejor vieja, y mi mejor viejo, cabrona. . . . sé que te caben muchas mujeres en el cuerpo y que yo sólo conocí a unas cuantas" (Arráncame 286,288). 
Vemos que Catí es una mujer de gran energía que ha participado en actividades que anteriormente se consideraban masculinas o trabajos del hombre, como la política; en su estado de viudez, demuestra también que es diferente de las otras mujeres. Normalmente una mujer viuda se considera sola y triste y piensa que sin el apoyo y la ayuda de su marido no podrá sobrevivir. En el caso de Catí, se ve que ella se siente libre porque ya no debe hacer las cosas que antes tenía que hacer con obligación y como comenta Mastretta sobre esto, “. . . es bastante libre porque es rica” (Citada por Anderson: 23).

Catalina se da cuenta de la crueldad de Andrés y sus asesinatos, pero decide ayudarle porque ella misma desea mantener su posición social como esposa del gobernador y le encanta la vida de una mujer rica (Fornet 120). Trata de independizarse, una vez, y deja a Andrés partiendo a Oaxaca. Este acto de rebeldía dura sólo horas, "Quería irme lejos, hasta pensé en ganarme la vida con mi trabajo, pero antes de llegar al primer pueblo ya me había arrepentido. . . No me gustó mi nueva vida. . . Regresé pronto, y me dio gusto entrar a mi casa" (Arráncame 72).

Catalina está confundida y no quiere aceptar las crueldades de Andrés pero al mismo tiempo no puede volver a su vida de antes porque ya está acostumbrada a vivir comfortablemente y a tener todo lo que quiere. Cuando observa a la gente pobre y sucia alrededor de ella, se recuerda de su vida como hija de un campesino y se da cuenta que no quiere vivir de esa manera otra vez. Ella comprende que aunque no esté contenta, todavía tiene más oportunidades y poder que la mujer de la clase baja. 
Además, como menciona Bailey, "Ser la esposa de Andrés le da una voz aunque sea una voz moldeada por el discurso hegemónico y patriarcal. Voz prestada: es la única a la que tiene acceso, pero voz al fin" (140).

También en otra ocasión podemos ver su lazo con la clase social de Andrés y sus intereses cuando se compara con la cocinera de su casa (Anderson 23) diciendo, 'Estaba medio enamorada de Andrés. Tenía mi edad y un hijo viviendo con su mamá en San Pedro. Se veía vieja. Le faltaban dos dientes y nunca se puso a dieta ni fue a la gimnasia ni se compró cremas caras. Parecía veinte años más vieja que yo. No me quería nada y tenía razón" (Arráncame 206).

Por lo tanto, ser la viuda de Andrés significa independencia porque ya no tiene a Andrés que la controle o mate a sus amantes. Ahora ella no sólo tiene el privilegio social por su imagen de ser la "esposa perfecta", sino que es una mujer rica por pertenecer a un nivel social alto. Una mujer viuda en el velorio de Andrés le asegura a Catalina un estado feliz y libre:

Me da gusto por ti. La viudez es el estado ideal de la mujer. Se pone al difunto en un altar, se honra su memoria cada vez que sea necesario y se dedica uno a hacer todo lo que no pudo hacer con él en vida. Te lo digo por experiencia, no hay mejor condición que la de viuda. Y a tu edad. Con que no cometas el error de prenderte a otro luego luego, te va a cambiar la vida para bien. (Arráncame 297) 
En realidad la muerte de Andrés no es un fin para Catalina sino que su vida empieza con su muerte y el consejo de la mujer viuda le da más confianza. Ella también está de acuerdo con ese comentario y dice, "Cuántas cosas ya no tendría que hacer. Estaba sola, nadie me mandaba. Cuántas cosas haría, pensé bajo la lluvia a carcajadas. Sentada en el suelo, jugando con la tierra húmeda que rodeaba la tumba de Andrés. Divertida con mi futuro, casi feliz" (Arráncame 305).

Se ve que Catalina no puede llorar por Andrés y sólo llora por costumbre ya que esto era "correcto" para la viuda de un gobernador. Ella comenta acerca de eso, 'Yo quise recordar la cara de Andrés. No pude... . Me sentí libre. ... Pensé en Carlos, en que fui a su entierro con las lágrimas guardadas a la fuerza. A él podía recordarlo: exactas su sonrisa y sus manos arrancadas de golpe. Entonces, como era correcto en una viuda, lloré más que mis hijos" (Arráncame 305). Como Carlos era su verdadero amor, ella siempre lo recuerda y puede sentir la pena de perderlo y en cambio sus sentimientos hacia Andrés eran una combinación de amor y odio. Amor por sentirse protegida y amada y el odio por saber lo que hacía Andrés, que mataba a la gente que se le oponía. Todo para él era la política.

Anderson describe la novela de Mastretta así, 'In fine, Arráncame la vida represents the education and transformation of Catalina Guzmán, not into the woman that the dominant social scripts would have her be, but rather into the intelligent and independent widow who is "divertida con mi futuro, casi feliz" (18). 
Al comparar estas dos novelas las de Bombal y Mastretta quiero referirme a algunas de las ideas de las femenistas europeas ya que María Luisa por haber vivido y estudiado en Francia tiene influencia europea en su obra. Al mismo tiempo Mastretta por haber viajado mucho por Europa también puede caber en esta categoría del femenismo europeo. Otra razón por concentrarme en el femenismo europeo en vez del femenismo norteamericano es por tener más conocimiento sobre las feministas europeas como Kristeva, Cixous, Irigaray, Gilbert y Gubar.

Bombal y Mastretta al escribir La última niebla y Arráncame la vida presentan la situación de la mujer en la sociedad patriarcal y los problemas que ésta tiene que confrontar. Como hemos observado, la protagonista de Bombal al final de la novela decide seguir su vida sin ningún cambio y así queda en la misma situación que estaba al comienzo de la novela.

En esta posición de dependencia y seguridad que el matrimonio le ofrece, ella considera la muerte como la única solución ya que la huida sería una rebelión contra los valores de la sociedad patriarcal (Guerra-Cunningham, Narrativa 51). Podemos observar este punto cuando dice, "No me siento capaz de huir. De huir, ¿Cómo, a dónde? La muerte me parece una aventura más accesible que la huida. De morir, sí, me siento capaz" (Última 18).

Vemos una falta de alternativa para la mujer en las dos novelas. Ellas no pueden dejar a su marido y terminar con su matrimonio porque económicamente no pueden sobrevivir. Las dos protagonistas pertenecen a la clase alta de la sociedad por 
estar casadas con hombres ricos. Además, en los años 30 una mujer divorciada o solterona perdía su posición social ya que el matrimonio era el centro de la vida para una mujer.

Por otro lado, aunque Catalina ha sufrido también en su matrimonio, al mismo tiempo ha tenido una gran educación. Como esposa de un gobernador ha visto desde arriba la política y la sociedad en general. Con esto ha madurado enormemente. Al principio de la novela ella era una chica inocente que sólo obedecía las órdenes de Andrés "un dios" sin preguntar nada. Esto se ve cuando dice, "Yo al principio no sabía de nadie. Andrés me tenía guardada como un juguete con el que platicaba de tonterías, al que se cogía tres veces a la semana y hacía feliz con rascarle la espalda y llevar al zócalo los domingos" (Arráncame 37). Al final de la novela, ella ha llegado a ser una mujer madura, inteligente e independiente quien está contenta de su viudez y de un futuro sin marido.

Como he mencionado antes, escribir es una manera que la mujer usa para expresar sus sentimientos y sus problemas. Bombal y Mastretta también presentan diferentes posibilidades para la mujer. Se ve que Mastretta da una vida más activa a la mujer y trata de romper los estereotipos. Su protagonista participa en los asuntos políticos que normalmente se considera trabajo del hombre. En Bombal es dificil para la mujer salirse del molde. La sociedad no la deja, la autora tampoco.

La visión de las feministas sobre la importancia del lenguaje es que el lenguaje es una manera de liberación para la mujer aunque hay una diferencia entre la escritura 
femenina y masculina. Cixous cree que el lenguaje ha sido un elemento fundamental para la opresión de la mujer y menciona que la mujer tiene que escribir sobre su cuerpo y su sexualidad para desafiar el pensamiento masculino (Sellers 25).

Cixous, dice Sellers, "sees man's will for power as the mainstay of Western ideology, founding and perpetuating our social, political and cultural status quo. ... the only way forward is to tear down this 'vast membrane' fabricated by the masculine, overcoming its repressions through the inventive posibilities of language" (16).

Tener un lenguaje propio no quiere decir ignorar el otro sexo o tener un lenguaje superior dice Wiegel, “. . . significa plantear 'una feminidad otra pero autónoma', . . , abriéndose la posibilidad de idear o construir imágenes literarias de mujeres que provengan de las propias mujeres. Esto significa procurar encontrar las estrategias asumidas por las mujeres escritoras para dar cuenta de historias de mujeres" ( Citada por Malverde Disselkoen: 69-70).

Mastretta cree que los temas literarios pueden ser elegidos por un escritor o una escritora a pesar de los estereotipos que el amor y la pasión han sido temas femeninos. Los temas del poder, el odio y la guerra también pueden ser elegidos por una escritora igual que un escritor. Ella menciona, "The works that move the world - those that captivate it to the point of becoming part of our collective memory - are those that are well written, not those written by men or by women" (Beer 17).

A pesar del comentario de Mastretta, con el cual estoy de acuerdo, en que una obra no puede ser juzgada basándose en el sexo de su autor, al mismo tiempo creo que 
hay una diferencia en la técnica, en el uso de los símbolos y el cuerpo de la mujer, en una obra escrita por un hombre y una mujer. Martha Traba afirma que la escritura femenina es más directa y emotiva y la literatura masculina es, "más especulativa, más capaz de armar un panorama general que englobe los detalles, más impúdica en la confesión de relaciones humanas, .. La femenina, . . , resulta más emocional, mejor dotada para ver los detalles que la totalidad, más púdica (o romántica) para contar la relación amorosa" (Citada por García Pinto: 43).

Evaluando La última niebla según estas carasterísticas, Amado Alonso dice, "Ia novela es una manifestación de escritura auténticamente femenina precisamente por lo que él designa como el <<eficaz elemento expresivo de este halo sentimental y fantástico $>>$ y el $<<$ peculiar modo emocional $>$ en que se inscribe" (Citado por Oyarzún:164). Además Alonso está contento de que Bombal no haya sido influida por la escritura masculina, “iQué suerte que el oficio masculino de escribir no haya masculinizado a una escritora más!" (164).

López Morales dice de la escritura femenina y de la obra de Bombal, 'Women's writing is self-censored . . , the explicit nature of the woman's body in La última niebla breaks the self-censorship of the subject. This rupture enables a poetics of the body in whose speech its images and necessities are integrated" (Citado por GuerraCunningham, Splintering: 124-125).

Hemos visto que la belleza de la mujer y su cuerpo tiene mucha importancia en la obra de Bombal y como afirman Irigaray y Cixous, "if women are to discover and 
express who they are, to bring to the surface what masculine history has repressed in them, they must begin with their sexuality. And their sexuality begins with their bodies, with their genital and libidinal difference from men" (Citadas por Newton: 91).

Annie Leclerc, como menciona Sellers, quiere inventar un lenguaje propio para la mujer y piensa que la única forma que la mujer puede expresar su experiencia como mujer es a través de su sexualidad y su cuerpo. Leclerc cree, "It's only from here that a new word can be born which will be women's" (Citada por Sellers: 29).

Carolyn Heilbrun piensa que, "There is no room for a feminist viewpoint . . . There is no male or female viewpoint; there is only the human viewpoint, which happens always to have been male" (Citada por Morris: 42).

La mujer siempre ha sido nombrada como 'el otro.' Irigaray explica este concepto diciendo, ". . , the woman is viewed by the man as his opposite, that is to say, as his other, the negative of the positive, and not, in her own right, different, other, otherness itself' (Citada por Felman: 23). Por lo tanto, la mujer marcada como 'el otro' existe en un mundo donde el hombre es el sujeto y como consecuencia ella se convierte en un objeto hasta para ella misma y eso causa la alineación y la pérdida de la identidad como hemos visto en la obra de Bombal (Miller 284-285).

Todas las críticas feministas piensan que la sexualidad no es algo inato, que la mujer nace para ser mujer y el hombre nace con cualidades para ser hombre, sino que estas características se desarrollan a través del contacto del individuo con la familia. Los padres quienes han aceptado estos papeles tratan de enseñarlos a los hijos también; 
por lo tanto, "sexuality is not a natural given, but rather is the consequence of social interactions, among people and among signs" (Newton 91-92). Virginia Woolf cree que la meta de la lucha de las feministas debe ser 'to deconstruct the death-dealing binary oppositions of masculinity and femininity" (Moi 13).

Ya que la mujer siempre ha sido considerado como 'el otro' y el negativo, en el discurso patriarcal también tiene la misma posición. Irigaray menciona esto, "patriarcal discourse situates woman outside representation: she is absence, negativity, the dark continent, or at best a lesser man. In patriarcal culture the femenine as such ... is repressed; it returns only in its 'acceptable' form as man's specularized Other" (Citada por Moi: 133).

Por lo tanto, lo que las mujeres dicen, escriben o imaginan siempre ha sido asociado con lo negativo y de no importancia y así el discurso femenino no es parte natural del discurso (Smith 36). Además, lo dicho por la mujer se relaciona con la locura y el silencio. Ya hemos hablado sobre el tema de silencio en las dos novelas, como técnica narrativa, que las autoras usan para decir lo que no se puede decir con palabras. Felman apunta, "Women as such are associated both with madness and with silence, whereas men are identified with the prerogatives of discourse and of reason. In fact, men appear not only as the possessors, but also as the dispensers, of reason, which they can at will mete out to - or take away from - others" (32).

Durante años los eventos sociales y políticos han sido elementos que ayudaron a la mujer para darse cuenta de su individualidad y de su sexualidad, oprimidos por la 
sociedad patriarcal. Además, estos eventos han tenido influencia en el discurso femenino y su lenguaje. Por ejemplo, en la obra de Mastretta vemos que Catalina usa un lenguaje que no es apropiado para la mujer y a veces suena como la palabra del hombre. Como menciona Anderson, "Cati's narration and dialogues are sprinkled with vulgarities and profanities that at times may seem incongruous with her social position" (21).

Tenemos que notar que Catí rompe los límites sociales en el uso del lenguaje, pero implícitamente responde a las reglas sociales. Por ejemplo, el uso del lenguaje vulgar es algo normal para un hombre y lo usa en el ámbito privado y público. Por otro lado, Catí sólo usa este lenguaje cuando habla con Andrés o Carlos y a veces con las mujeres del mismo nivel social que ella. Catí nunca usa el lenguaje vulgar cuando habla con mujeres de la clase trabajadora o en un ámbito público (Anderson 21).

Así, Catí al mismo tiempo que nos muestra el rol, el comportamiento, las actividades y la imagen apropiada para la mujer en la sociedad patriarcal, también trata de resistir y cambiar estos estereotipos que oprimen a la mujer (Anderson 22).

Este estereotipo en el uso del lenguaje y la superioridad del hombre sobre la mujer se ve en una conversación entre Catí y Andrés. Durante una cena en su casa Catalina se da cuenta de que su padre está metido en los asuntos de Andrés y decide enfrentarse con él, “ - No quiero que metas a mi papá en tus cosas. Déjalo que viva como pueda, no se ha muerto de hambre, no lo revuelvas - dije" (Arráncame 80). 
Andrés al oír esto no le hace caso y le responde con sarcasmo y dice, “ ¿Y desde cuándo los patos les tiran a las escopetas? - dijo riéndose -" (Arráncame 80).

En este momento Catí se da cuenta que ella no puede mandar a Andrés y si quiere algo de él tiene que usar otro lenguaje que no sea tan directo. De esta manera implícitamente reconoce la superioridad de Andrés como hombre (Anderson 20). Ella tenía que usar el lenguaje del ser inferior hacia un ser superior, "Lo odiaba cuando se portaba como mi patrón. Pero me aguanté y cambié el tono por uno que funcionara mejor: - Andrés, te lo pido por lo que más quieras. Te dejo que le regales el Mapache a Heiss, pero saca a mi papá de un lío con Amed"(Arráncame 81). 


\section{Conclusión}

En conclusión, vemos que la mujer todavía tiene que luchar para cambiar el sistema patriarcal, lo cual, está basado en los valores masculinos. Aunque el movimiento de las mujeres y las feministas han avanzado durante años recientes, pero la meta principal es crear un mundo donde la mujer tenga tantos derechos como el hombre. Irigaray hablando de la misión de la mujer dice, “ . . women must of course continue to struggle for equal wages and social rights, against discrimination in employment and education, and so forth. ... So it is essential for women among themselves to invent new modes of organization, new forms of struggle, new challenges" (165-166). La mujer al contrario del hombre tiene pocos modelos, por lo tanto, debe ir creándose sus propios.

Como hemos visto, nuestros protagonistas han cumplido esta misión según las circunstancias de los años 30 donde la única alternativa para la mujer era el casamiento. En el caso de la protagonista de Bombal, se ve que aunque al final ella no se libera, al menos se da cuenta de su propia situación. Una situación que la paraliza. La novela nos da una visión triste de su protagonista femenina. No hay respuesta a sus deseos. El matrimonio parece algo incompatible con la realización de sí mismo. La mujer se estanca o se pierde en el matrimonio. El sueño o la fantasía es la única avenida hacia el crecimiento personal (Williams 29). La esposa de Daniel se aleja más y más del mundo exterior buscando refugio en sí misma. 
En Arráncame vemos a una protagonista que en su matrimonio con Andrés lucha por sus derechos, madurando en el proceso. Ella rompe muchos de los estereotipos asignados a la mujer que limitan su desarrollo. Mastretta en el final abierto de la novela nos muestra a una viuda contenta con numerosas avenidas hacia el futuro. Vemos también algo básico y que hemos ya indicado en este estudio y tiene que ver con la personalidad de las protagonistas. La mujer de Daniel es esencialmente de un carácter pasivo mientras que la mujer de Andrés tiene un carácter fuerte. Me gusta el final de Arráncame porque da más esperanza a la mujer. 


\section{Bibliografia}

Adams, M. Ian. Three Authors of Alienation: Bombal, Onetti, Carpentier. Austin: U of Texas P, 1937.

Agosín, Marjorie. "Un recuerdo de María Luisa Bombal." Revista Interamericana de Bibliografia/Inter-American Review of Bibliography 30 (1980): 402-405.

---. Silencio E Imaginación: Metáforas de la escritura femenina. México: Editorial Katún, 1986.

---, Elena Gascón-Vera, and Joy Renjilian-Burgy, eds. María Luisa Bombal: Apreciaciones críticas. Tempe, AZ: Bilingual, 1987.

---. "Una biografia de una mujer novelada: María Luisa Bombal." Discurso Literario Spring 5 (1988): 325-334.

---. "La escritura subersiva: Charlotte Perkins Gilman y María Luisa Bombal." Alba de América 9 (1991): 109-20.

---. "Mujer, espacio e imaginación en Latinoamérica: Dos cuentos de María Luisa Bombal y Silvia Ocampo." Revista Interamericana de Bibliografia/InterAmerican Review of Bibliography 41 (1991): 627-33.

Anderson, Danny J. "Displacement: Strategies of Transformation in Arráncame la vida by Ángeles Mastretta." The Journal of the Midwest Modern Language Association Spring 21 (1988): 15-27.

Bailey, Kay E. "El uso de silencio en Arráncame la vida por Ángeles Mastretta." Confluencia Fall 7 (1991): 135-42.

Baker, Armand F. "El tiempo y el proceso de individuación en La última niebla." Revista Iberoamericana Apr.-Sept. 52 (1986): 393-415.

Beer, Gabriela de. "Interview with Ángeles Mastretta." Review: Latin American Literature and Arts Spring 48 (1994): 14-17. 
Bente, Thomas O. "María Luisa Bombal's Heroines: Poetic Neuroses and Artistic Symbolism." Hispanófila Sept. 28 (1984): 103-113.

Bianchi, Soledad. "María Luisa Bombal o una dificil travesía: Del amor mediocre al amor pasión." Atenea: Universidad de Concepción 451 (1985): 175-192.

Bombal, María Luisa. La última niebla. Barcelona: Seix Barral, 1988.

Borinsky, Alicia. "La historia y el círculo de la domesticidad." Discurso Literario Spring 5 (1988): 389-394.

Campbell, Margaret V. "The Vaporous World of María Luisa Bombal." Hispania 44 (1961): 415-419.

Chesler, Phyllis. Women and Madness. New York: Doubleday \& Company, 1972.

Chetwynd, Tom. Dictionary of Sacred Myth. London: The Aquarian Press, 1993.

Cirlot, J.E. A Dictionary Of Symbols. Trans. Jack Sage. New York: Philosophical Library, 1962.

Devine, Maureen. Woman and Nature: Literary Reconceptualizations. London: The Scarecrow Press, 1992.

Felman, Shoshana. What Does a Woman Want? Reading and Sexual Difference. Baltimore \& London: Johns Hopkins UP, 1993.

Felski, Rita. Beyond Feminist Aesthetics: Feminist Literature and Social Change. Cambridge: Harvard UP, 1989

Fernández, Magali. El discurso narrativo en la obra de María Luisa Bombal. Madrid: Pliegos, 1988.

Fornet, Jorge. "Arráncame la vida en la encrucijada." Casa de las Américas Jan.-Feb. 30 (1990): 119-24.

Gálvez Lira, Gloria. Maria Luisa Bombal: Realidad y fantasía. Maryland: Scripta Humanística, 1986. 
García Pinto, Magdalena. "Entrevista con Martha Traba." Hispamérica Aug. 38 (1984): 37-46.

Garrels, Elizabeth. "Ver y ser vista: La mirada fálica en La última niebla." Escritura Jan.-Dec. 16 (1991): 81-90.

Girard, René. Deceit, Desire and the Novel. Baltimore: Johns Hopkins UP, 1990.

Gligo, Agata. María Luisa: Sobre la vida de Maria Luisa Bombal. Santiago: Andrés Bello, 1985.

Gmutzmann, Rita. "Tres ejemplos de escritura femenina en América Latina." Letras de Deusto May-Aug. 19 (1989): 91-104.

Goic, Cedomil. La novela chilena: Los mitos degradados. Santiago: Editorial Universitaria, 1991.

Gold, Janet N. "Arráncame la vida: Textual Complicity and the Boundaries of Rebellion." Chasqui Nov. 17 (1988): 35-40.

Guerra-Cunningham, Lucía. Mujer y sociedad en América Latina. Santiago, Chile: Editorial Del Pacífico, 1980.

---. La Narrativa de María Luisa Bombal: Una visión de la existencia femenina. Madrid: Playor, 1980.

---. "Entrevista a María Luisa Bombal." Hispanic Journal Spring 3 (1982): 119-127.

---. "Visión de lo femenino en la obra de María Luisa Bombal: Una dualidad contradictoria del ser y el deber ser." Revista Chilena de Literatura Apr. 25 (1985): 87-99.

---, and Yvette E. Miller, eds. Splintering Darkness: Latin American Women Writers in Search of Themselves. Pittsburgh: Latin American Literary Review, 1990. ---. "Estrategias discursivas en la narrativa de la mujer latinoamericana." Escritura Jan.-Dec. 16 (1991): 115-22. 
---. "La marginalidad subversiva del deseo en La última niebla de María Luisa Bombal." Hispamérica Aug. 21 (1992): 53-63.

Gullón, M. Agnes. 'Descifrando los silencios de ayer: Cinco horas con Mario." Insula 396-397 (1979): 4.

Irigaray, Luce. This Sex Which Is Not One. Trans. Catherine Porter. Ithaca: Cornell UP, 1985.

Julian, Nadia. The Mammoth Dictionary of Symbols. New York: Carroll \& Graf, 1996.

Kostopulos-Cooperman, Celeste. The Lyrical Vision of María Luisa Bombal. London: Thamesis, 1988.

Kramer, Paul, and Robert E. McNicoll, eds. Latin American Panorama: An Anthology. New York: Putnam's, 1968.

Laurence, Patricia Ondek. The Reading of Silence, Virginia Woolf in the English Tradition. Stanford: Stanford UP, 1991.

Leacock, Eleanor, et al. Women in Latin America, An Anthology. Riverside, CA: Latin American Perspectives, 1979.

Llarena, Alicia. "Arráncame la vida, de Ángeles Mastretta: El universo desde la intimidad." Revista Iberoamericana Apr.-June 58 (1992): 465-75.

Loubet, Jorgelina. "María Luisa Bombal y el realismo mágico." Boletín de la Academia Argentina de Letras Jan.-June 53 (1988): 125-134.

Malverde Disselkoen, Ivette. "De La última niebla y La amortajada a La brecha." Nuevo Texto Crítico 2 (1989): 69-78.

Mastretta, Ángeles. Arráncame la vida. Madrid: Alfaguara, 1986.

Meyer, Michael C., and William L. Sherman. The Course of Mexican History. 3rd ed. New York: Oxford UP, 1987. 
Miller, Beth, ed. Women in Hispanic Literature: Icons and Fallen Idols. Berkley, Los Angeles \& London: U of California P, 1983.

Moi, Toril. Sexual/Textual Politics: Feminist Literary Theory. London \& New York: Methuen, 1985.

Montalvo, Yolanda. "La huella de Becquer en la obra de María Luisa Bombal." La Torre: Revista de la Universidad de Puerto Rico Oct.-Dec. 5 (1991): 443-59.

Morris, Pam. Literature and Feminism: An Introduction. London: Blackwell, 1993. Natella, Arthur A. "Algunas observaciones sobre el estilo de María Luisa Bombal en La última niebla." Explicación de Textos Literarios 3 (1974-75): 167-71.

Newton, Judith, and Deborah Rosenfelt, eds. Feminist Criticism and Social Change: Sex, Class and Race in Literature and Culture. New York \& Londen: Methuen, 1985.

Oyarzún, Kemy. "Ecolalia e intertextualidad en La última niebla." Discurso Literario Fall 4 (1986): 163-183.

Paz, Octavio. El laberinto de la soledad. México: Fondo de Cultura, 1986.

Pescatello, Ann, ed. Female and Male in Latin America: Essays. Pittsburgh: U of Pittsburgh P, 1973.

Rabago, Alberto. "Elementos surrealistas en La última niebla." Hispania Mar. 64 (1981): 31-40.

Rice, Mary. "La novela femenina del siglo XX: Bombal, Laforet y Martin Gaite." Mester Fall 15 (1986): 7-12.

Sellers, Susan. Language and Sexual Difference: Feminist Writing in France. New York: St. Martin's, 1991.

Showalter, Elaine, ed. The New Feminist Criticism: Essays on Women, Literature, and Theory. New York: Pantheon, 1985. 
Skidmore, Thomas E., and Peter H. Smith. Modern Latin America. New York: Oxford UP, 1984.

Smith, Dorothy E. El mundo silenciado de las mujeres. Santiago: Cide, 1986.

Tolliver, Joyce. "Otro modo de ver: The Gaze in La última niebla." Revista Canadiense de Estudios Hispánicos Fall 17 (1992): 105-21.

Urza, Carmelo. "Alienation and symbol in Mariotti's No Fundo, No Fundo and Bombal's La última niebla." Luso-Brazilian Review Summer 21 (1984): 89-98.

Walker, Barbara. The Woman's Encyclopedia of Myths and Secrets. New York: Harper \& Row, 1983.

Waller Orlandi, Claudia. "Mist, Light and the Libido: La última niebla." Kentucky Romance Quarterly 26 (1979): 231-241.

Williams, Loma V. "The Shrouded Woman: Marriage and Its Constraints in the Fiction of María Luisa Bombal." Latin American Literary Review SpringSummer 10 (1982): 21-30. 